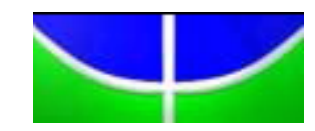

UNIVERSIDADE DE BRASÍLIA - UNB

INSTITUTO DE RELAÇÕES INTERNACIONAIS - IREL

PROGRAMA DE PÓS-GRADUAÇÃO EM RELAÇÕES INTERNACIONAIS

ESPECIALIZAÇÃO EM RELAÇÕES INTERNACIONAIS

ÉRCOLE TRAMONTANO

A COOPERAÇÃO TÉCNICA INTERNACIONAL NO SETOR POSTAL: A EMPRESA BRASILEIRA DE CORREIOS E TELÉGRAFOS COMO AGENTE DE COOPERAÇÃO TÉCNICA PRESTADA 


\title{
A COOPERAÇÃO TÉCNICA INTERNACIONAL NO SETOR POSTAL: A EMPRESA BRASILEIRA DE CORREIOS E TELÉGRAFOS COMO AGENTE DE COOPERAÇÃO TÉCNICA PRESTADA
}

\author{
Trabalho de Conclusão de Curso de \\ Relações Internacionais para o \\ Instituto de Relações Internacionais \\ da Universidade de Brasília \\ apresentado como requisito parcial à \\ obtenção do título de Especialista em \\ Relações Internacionais.
}

Orientador:

Prof. Dr. Antonio Carlos Lessa 
TRAMONTANO, Ércole.

A cooperação técnica internacional no setor postal: a Empresa Brasileira de Correios e Telégrafos como agente de cooperação técnica prestada. Ércole Tramontano; Orientador: Prof. Dr. Antonio Carlos Lessa - Brasília, 2010.

$55 \mathrm{p}$.

Trabalho de Conclusão de Curso. Instituto de Relações Internacionais/Universidade de Brasília. Curso de Especialização em Relações Internacionais.

1. Cooperação 2. Ações 3. Política externa.

Instituto de Relações Internacionais 
À Ivonete, minha vida e meu amor, do plano de onde estiver pela sua infinita dedicação e permanente incentivo. 


\section{AGRADECIMENTOS}

O desenvolvimento de um trabalho técnico como a monografia é a última etapa de um processo de aprendizagem e aperfeiçoamento pessoal e profissional a que o autor se propôs. Este processo exige dedicação, persistência, resiliência e motivação para alcance dos resultados.

Importante para a consecução dos seus objetivos é o contorno familiar e de pessoas queridas que estejam acompanhando e incentivando-nos para chegarmos ao nosso objetivo. Meses de estudos, leituras e pesquisas requerem o 'isolamento' e muitas vezes, por esse período, nos tornamos antissociais.

Agradecer é uma tarefa muito pouco praticada pelas pessoas e não me eximo deste hábito pouco saudável. Seria, entretanto, impossível deixar de registrar o apoio e incentivos incondicionais que recebi ao longo do último ano para alcançar, com êxito, a conclusão do XI Curso de Especialização em Relações Internacionais da Universidade de Brasília.

Ao Professor Antonio Carlos Lessa, meu orientador, cujo conhecimento no campo das Relações Internacionais trouxe grande solidez ao desenvolvimento deste trabalho, seja pela disciplina ministrada no Curso, seja pela maneira inteligente de orientar o estudo e, ainda, pela capacidade de manter a motivação, principalmente em momentos críticos, quero registrar o meu "muito obrigado".

Ao Allan Victor, meu filhão, meu parceiro, meu amigo, agradeço pela compreensão por não podermos estar mais tempo juntos e por não deixar que a indisponibilidade temporária afetasse o nosso relacionamento.

À Elaine, carinhosamente 'Neguinha', sempre presente - apesar da distância - e preocupada com que tudo esteja bem, grande incentivadora e apoiadora, agradeço pela atenção e pelo carinho permanentes.

À Dra. Mercês, minha grande amiga, profissional excelente, que várias vezes me emprestou seus 'anjinhos' para que me dessem luz e inspiração no desenvolvimento deste trabalho, agradeço pelo apoio e pelo carinho que me são deferidos.

Ao meu amigo João, pela inteligência e pela capacidade de ouvir mesmo aos assuntos pouco empolgantes, agradeço pelo estímulo que lhe é característico.

À minha mãe e ao Manoel, pelo caminho do estudo que me indicaram como a estrada para alcance do crescimento pessoal e profissional e pela educação, ética, princípios e valores que sempre me nortearam.

Agradeço também a minha amiga Taís pelo carinho e pelo incentivo que me dispensa e pela paciência e compreensão de ter um amigo tão ausente.

Ao Siciliano, meu ex-chefe e sempre amigo, profissional de excelência e grande conhecedor da área internacional, incentivador e apoiador para que eu realizasse este Curso, meu efusivo obrigado também pelos ensinamentos que me passou como líder e como ser humano.

Claro, não poderia deixar de agradecer a Deus pelas bênçãos que recebo, pois, em sendo tantas, superaram a quantidade de páginas deste trabalho. 


\section{RESUMO}

O presente estudo investiga a atuação da Empresa Brasileira de Correios e Telégrafos no contexto da cooperação técnica internacional. Este trabalho tem a pretensão de verificar se é possível caracterizar essa Empresa pública como partícipe do Governo nas ações de cooperação levadas a cabo pelo Brasil. O estudo analisa o Setor Postal do ponto de vista global, identifica Organização Internacional catalisadora e estimuladora de ações de cooperação no âmbito postal e avalia a participação da Empresa Brasileira de Correios e Telégrafos quanto à aderência à política externa do Brasil no tema de cooperação técnica prestada no segmento postal.

Palavras-Chave: Cooperação Técnica, política externa, setor postal. 


\begin{abstract}
This research aims at analyzing the initiatives taken by Empresa Brasileira de Correios e Telégrafos (henceforward named ECT) within the framework of the international technical cooperation, in order to ascertain whether ECT, as a public enterprise, can be deemed as a government participant under the scheme of cooperation initiatives carried out by Brazil. Besides this, the research is focused on the postal sector from a global viewpoint and deals with an international organization under whose auspices international cooperation initiatives within the postal sphere are speeded up and spurred on. Finally, the role played by ECT is assessed as to its adherence to the foreign policy affairs carried out by Brazil under the technical cooperation issues concerning the postal area.
\end{abstract}

Key-Words: Technical Cooperation, foreign policy, postal sector. 


\section{LISTA DE ABREVIATURAS E SIGLAS}

ABRAED - Associação Brasileira de Empresas de Distribuição

ADPF - Arguição de Descumprimento de Preceito Fundamental

AH - Assistência Humanitária

AICEP - Associação dos Operadores de Correios e Telecomunicações dos Países e Territórios de Língua Oficial Portuguesa

AOD - Assistência Oficial ao Desenvolvimento

AT - Assistência Técnica

CA - Conselho de Administração

COP - Conselho de Operações

CTPD - Cooperação Técnica entre Países em Desenvolvimento

BRIC - Brasil, Rússia, Índia e China

CC\&T - Cooperação Científica e Tecnológica

CF - Cooperação Financeira

CLT - Consolidação das Leis do Trabalho

CT - Cooperação Técnica

CTI - Cooperação Técnica Internacional

DCT - Departamento de Correios e Telégrafos

EPMB - Estratégia Postal Mundial de Bucareste

EPN - Estratégia Postal de Nairobi

ECT - Empresa Brasileira de Correios e Telégrafos 
FUNAG - Fundação Alexandre de Gusmão

GPS - Gerenciamento de Pessoal Simplicado

ICPD - Instituto CEUB de Pesquisa e Desenvolvimento

IDH - Índice de Desenvolvimento Humano

MC - Ministério das Comunicações

MRE - Ministério das Relações Exteriores

ONU - Organização das Nações Unidas

OTAN - Organização do Tratado do Atlântico Norte

PED - Países em Desenvolvimento

PI - Países Industrializados

PIDEP - Plano Integral de Reforma e Desenvolvimento Postal

PMA - Países Menos Avançados

PNAD - Pesquisa Nacional por Amostra de Domicílios

PNUD - Programa das Nações Unidas para o Desenvolvimento

RPN - Rede Postal Aérea Noturna

SEPLAN - Secretaria de Planejamento da Presidência da República

UIT - União Internacional de Telecomunicações

UNICAMP - Universidade Estadual de Campinas

UPAEP - União Postal das Américas, Espanha e Portugal

UPU - União Postal Universal 
SUMÁRIO

INTRODUÇÃO

1. A COOPERAÇÃO TÉCNICA INTERNACIONAL .......................................13

2. O SETOR POSTAL MUNDIAL E A COOPERAÇÃO TÉCNICA INTERNACIONAL ........................................................................................22

3. O SETOR POSTAL NO BRASIL, A EMPRESA BRASILEIRA DE CORREIOS E TELÉGRAFOS E A INSERÇÃO INTERNACIONAL ...............28

4. PERFORMANCE DA ECT COMO AGENTE DA POLÍTICA DE COOPERAÇÃO INTERNACIONAL DO BRASIL ...............................................33

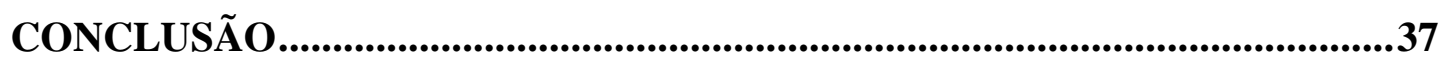

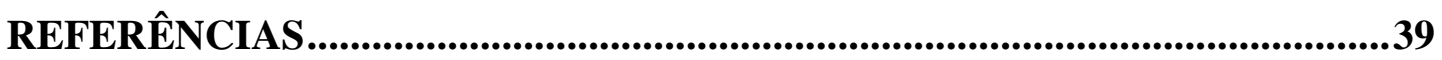

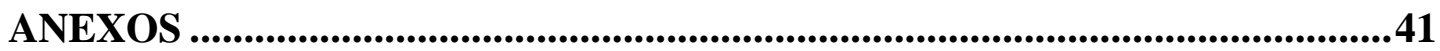

ANEXO 1 - QUADRO ESTRUTURAL DA ESTRATÉGIA POSTAL DE NAIROBI .......................................................................................................42

ANEXO 2 - ORGANOGRAMA DA EMPRESA BRASILEIRA DE CORREIOS

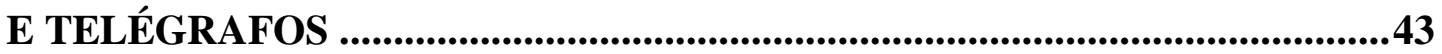

ANEXO 3 - RELAÇÃO DOS PAÍSES ONDE HOUVE A FORMULAÇÃO DO PIDEP.............................................................................................................44

ANEXO 4 - RELAÇÃO DAS AÇÕES DE COOPERAÇÃO TÉCNICA INTERNACIONAL PRESTADAS PELA EMPRESA BRASILEIRA DE CORREIOS E TELÉGRAFOS NO PERÍODO DE 1995 A 2009..........................45

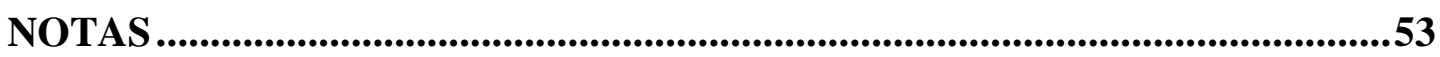




\section{INTRODUÇÃO}

"Nada existe de permanente, exceto a mudança." Heráclito, 500 a.C.

O novo milênio traz, à reboque, desafios e inovações em todos os campos que se refletem na vida moderna. Por certo, o início do Século XX também trazia incertezas e expectativas que a História trouxe à tona.

O que substancialmente distingue os processos de mudança no novo milênio é a velocidade com que acontecem e com que se propagam.

O Setor Postal mundial não é impactado diferentemente. O que era mero envio de cartinha de cunho social, no mundo globalizado de hoje é um complexo processo de captação, tratamento, transporte e distribuição perfazendo um ciclo logístico eminentemente comercial.

Com uma característica singular, os serviços postais estão presentes em todas as Nações e a sua execução é responsabilidade do Estado. É, também, de interesse dos países que a prestação dos serviços de correios seja adequada, segura, regular e rápida, afinal, a sua 'exportação' de remessas postais - sejam documentos ou encomendas - dependerá da qualidade da prestação dos serviços dos serviços postais dos outros países quando destinados "além fronteiras".

Nesta dinâmica, reluz a cooperação técnica como ferramenta redutora do gap de desenvolvimento entre os países no âmbito do Setor Postal.

A cooperação técnica é também um poderoso instrumento de política externa e, para o Brasil, uma ferramenta de projeção e de oportunidades.

Motivou o desenvolvimento deste estudo, apreciar se é possível caracterizar a Empresa Brasileira de Correios e Telégrafos como agente do Governo nas ações de cooperação técnica. Uma vez que a Empresa tem know-how e integra uma comunidade internacional assimétrica na prestação de serviços postais e tratando-se de uma Empresa Pública é de se esperar que esteja alinhada e aderente à política do Governo Federal na participação de ações de cooperação técnica internacional. 
No primeiro capítulo estudou-se sobre os primórdios da cooperação técnica, indicando as diferenças entre as modalidades de cooperação para o desenvolvimento e focando a macro visão da cooperação técnica internacional e a correlação com a política externa do Brasil, constatando-se que a cooperação não é uma ação ou um conjunto de ações isoladas mas um processo que integra uma estratégia ampla e assertiva.

Importante destacar, ainda neste primeiro capítulo, a Agência Brasileira de Cooperação. Parte integrante da estrutura do Mistério das Relações Exteriores é o órgão executor da política de cooperação técnica do governo brasileiro com base na análise de adequabilidade dos projetos às prioridades, planos e programas nacionais de desenvolvimento bem como aos programas negociados com os organismos internacionais e agências de desenvolvimento de países parceiros.

No segundo capítulo o trabalho estuda o Setor Postal mundial e a Cooperação Técnica internacional. Há uma caracterização e identificação dos contornos e periferia do denominado Setor Postal, quem são os atores que nele atuam e identifica a União Postal Universal como Organização catalisadora e reguladora dos serviços postais no mundo e cujo propósito sólido é o de promover o desenvolvimento postal utilizando a sua principal ferramenta: a cooperação técnica.

No terceiro capítulo, o estudo foca o Setor Postal no Brasil e apresenta o seu principal player: a Empresa Brasileira de Correios e Telégrafos. Como Empresa estatal, é a responsável pelo cumprimento das diretrizes governamentais nas ações de cooperação técnica no âmbito do Setor Postal internacional, seja de forma bilateral como multilateral, principalmente nas ações conjuntas com a União Postal Universal da qual o Brasil é País-membro.

No quarto e último capítulo, o estudo analisa a performance da Empresa Brasileira de Correios e Telégrafos e sua aderência à política de cooperação técnica internacional, à luz do cenário nacional - política de relações exteriores do país, participação nas ações de cooperação e nos resultados decorrentes - e do cenário internacional - compromissos assumidos junto a Organizações internacionais, acordos bilaterais firmados pelo Itamaraty ou pela própria ECT, efetividade da participação da Empresa junto aos países recebedores de cooperação técnica - 
buscando identificar em que medida a cooperação praticada pela Empresa Brasileira de Correios e Telégrafos mostra-se efetiva como instrumento de ação externa.

A conclusão procurará sintetizar do estudo desenvolvido a resposta ao questionamento objeto deste trabalho, ou seja, se é possível caracterizar a Empresa Brasileira de Correios e Telégrafos como agente do Governo nas ações de cooperação técnica.

A metodologia utilizada para este estudo foi a pesquisa de abordagem qualitativa calcada na pesquisa bibliográfica cujos dados coletados são descritivos, sem utilização de dados estatísticos como centro do processo de análise.

Grande ênfase foi direcionada aos trabalhos acadêmicos sobre o tema por dois motivos. Primeiro porque pesquisas técnicas foram previamente realizadas analisando a cooperação técnica e o conhecimento disponibilizado agrega grande valor ao foco deste estudo. Em segundo porque o tema cooperação técnica é muito pouco explorado na literatura brasileira sendo geralmente tratado de forma acessória pela bibliografia disponível.

A revisão da literatura passou por um longo período de seleção, leitura, “discussão com o autor”, compreensão, descarte e resumo analítico (fichamento) das obras consultadas. Foram buscadas informações na Empresa Brasileira de Correios e Telégrafos, na União Postal Universal (via site e via email), na Biblioteca da Universidade de Brasília e em vários sites da internet.

No espaço temporal os levantamentos de dados foram definidos para o período 1995 - 2009 para que pudessem embasar a resposta à questão foco do estudo.

Ao desenvolver este estudo é pretensão contribuir positivamente para o aprimoramento da Empresa Brasileira de Correios e Telégrafos no vetor estratégico das relações internacionais. 


\section{A COOPERAÇÃO TÉCNICA INTERNACIONAL}

Ao fim da Primeira Guerra Mundial (1914-1918), todas as Nações participantes ou não do conflito belicoso - se questionavam sobre as causas, os efeitos e principalmente sobre o futuro dos países em relação à paz mundial.

Em 1919, foi assinado o Tratado de Versalhes que estabeleceu a criação da "Liga das Nações", uma organização internacional que "nasceu de uma idéia remota da solução de controvérsias e de cooperação internacional" (CERVO, 1994 apud SARAIVA (Org.), 2008, p. 142).

Composta inicialmente por 32 países e tendo ao longo de sua existência (1919-1946) a associação de 63 países, a Liga ou Sociedade das Nações compunhase de um Conselho, com membros permanentes e eleitos, uma Assembléia e um Secretariado, instalados em Genebra, além da Corte Internacional de Justiça instalada em Haia. Sua missão, basicamente, voltava-se a promover o desarmamento, a paz e a segurança mútua de seus membros ${ }^{1}$.

Alguns êxitos e uma relevante quantidade de fracassos ocorridos durante os 27 anos de existência da Liga corroboraram para que o Organismo fosse desconstituído em 1946.

A insurgência da Segunda Grande Guerra Mundial (1939-1945) foi definitiva para a desacreditação da Liga como organismo representativo das Nações. Estados Unidos e o Reino Unido firmaram, em agosto de 1941, a Carta do Atlântico ${ }^{2}$ que foi o embrião para a criação da Organização das Nações Unidas (ONU), oficialmente constituída em 1945 depois que 50 países, reunidos em São Francisco, EUA, no encontro denominado Conferência das Nações Unidas para uma Organização Internacional, elaboraram a Carta das Nações Unidas, assinada em junho de 1945 e ratificada, em 24 de outubro de 1945, por 51 países signatários ${ }^{3}$ declarados membros originários da ONU.

Com uma proposta distinta, a Organização então criada tinha bases mais realistas, com fulcro na preservação e respeitabilidade aos países vitoriosos na Segunda Grande Guerra Mundial e a afirmação jurídica do fim do ciclo de predominância da sociedade internacional européia ${ }^{4}$. 
A recuperação dos países, o alcance do desenvolvimento e a erradicação de conflitos belicosos transformaram-se na obsessão da Organização das Nações Unidas, hoje integrada por 192 países. Como bem nos recorda o Prof. José Flávio Sombra:

\footnotetext{
"A nova ordem internacional seria, pois, tributária do ideário panamericano de pacifismo e cooperação internacionais entre Estados soberanos, sem ignorar a existência da desigualdade de status e de responsabilidades entre as potências" (SARAIVA (Org.), 2008, p. 193).
}

A consecução dos objetivos da ONU passa necessariamente por instrumentos concretos de cooperação internacional. A Assembléia Geral das Nações Unidas estabeleceu formalmente, por intermédio da Resolução $\mathrm{n}^{\circ} .200$ de dezembro de 1948 a "Assistência Técnica" (AT), de essência não-lucrativa e desvinculada de condicionantes econômicos e comerciais, para alcance dos propósitos daquela Organização.

A designação "Assistência", no entanto, tomou uma conotação pejorativa, de domínio e subserviência, caracterizando a assimetria latente entre o país doador e o recipiendário. A Assembléia Geral das Nações Unidas, quando da realização da $14^{\mathrm{a}}$ Sessão Ordinária (1959), alterou o nome "assistência" para "cooperação", passando a entender este processo a partir do ponto de vista do país recebedor, sugerindo equalização e diálogo entre os dois países e atribuindo aos projetos de cooperação um caráter de aliança, orientado primordialmente às necessidades do país recipiendário ${ }^{5}$.

A motivação da cooperação técnica internacional por parte dos países recebedores é relativamente evidente. Está inserida na própria acepção do termo “cooperação para o desenvolvimento" trazendo-lhes subsídios e recursos que possam contribuir para a promoção e o alcance do progresso social e econômico, com resultados em favor da sociedade.

A esse respeito bem ilustra Fernando Vieira Machado sobre a Cooperação Técnica Internacional em sua dissertação:

“A CTI, originalmente, possui como característica fundamental a transferência de técnicas e conhecimentos de forma não-comercial para reduzir a diferença de nível de desenvolvimento alcançado entre doador e prestador através de execução conjunta de projetos envolvendo especialistas, treinamento e capacitação de pessoal, elaboração de 
material bibliográfico, aquisição de equipamentos, realização de estudos e pesquisas" (MACHADO, 2004).

Não obstante o caráter donativo e desvinculado de condicionantes interposto pela ONU, o país doador de cooperação técnica, em não raras vezes, substitui o enfático discurso oficial de motivação ética, altruísta, humanitária e benevolente por ações de interesses políticos, geoestratégicos, econômicos ou comerciais e, com mais ênfase após o ato terrorista de 11 de setembro de 2001, de segurança nacional para a oferta de suas ações de cooperação técnica a outros países.

Os países desenvolvidos não devem atribuir a cooperação para o desenvolvimento como instrumento principal para salvaguardar interesses políticos e estratégicos juntos aos países em desenvolvimento. Para isso, dispõe a diplomacia de várias ferramentas no escopo das relações internacionais ${ }^{6}$.

Vista de uma maneira pragmática, a realidade nos faz inferir que tanto o interesse político quanto o estratégico assumem funções preponderantes na definição do tipo de cooperação, do país beneficiário, do alcance, extensão, execução e resultados esperados para a concessão da cooperação técnica.

Muitas das ações de cooperação para o desenvolvimento que evidenciam motivações comerciais ou econômicas por parte dos países doadores são aquelas identificadas por "cooperação atada" (“Tied Aid"), caracterizadas pela existência de pré-condições impostas pelo país doador ao recipiendário como, por exemplo, que parcela dos recursos transferidos sejam utilizados para aquisição de produtos ou serviços do país doador.

Outras motivações podem capear o interesse de prestar cooperação: morais, históricas, culturais, ambientais e decorrentes de fluxos migratórios. Ratificando o entendimento do uso interessado da cooperação fora do conceito puro pregado pela ONU, vale reportar ao artigo do ilustre Prof. Luiz Amado Cervo:

\footnotetext{
“A inserção da CTI no sistema internacional ocorreu com as modificações introduzidas no imediato pós-guerra, entre 1945-1949. Falava-se, então em 'ajuda' para a reconstrução da Europa e para o desenvolvimento, porém, as duas superpotências, Estados Unidos e União Soviética, tinham em vista, antes de tudo, a montagem de seus sistemas de aliança (Organização do Tratado do Atlântico Norte - OTAN e Pacto de Varsóvia), bem como a preservação das zonas de influência com que haviam organizado o espaço terrestre. A CTI nasceu, portanto, em contexto estratégico, não tendo como único escopo o que lhe era próprio,
} 
mas algo mais e distinto. Essa ambivalência entre fins próprios e a função derivada manter-se-á pelas décadas seguintes" (CERVO, 1994, p. 89).

Tecnicamente inexiste uma classificação formal indicativa das modalidades de cooperação para o desenvolvimento. Na bibliografia pesquisada e na prática dos países encontram-se a Cooperação Financeira (CF), a Assistência Humanitária (AH), a Ajuda Alimentar, a Cooperação Científica e Tecnológica ${ }^{7}$ e a Cooperação Técnica (CT).

A Cooperação Financeira (CF) é composta pelo conjunto de subvenções, doações (inclusive de bens), investimentos a fundo perdido, créditos "concessionais" de longo prazo e com baixa taxa de juros geralmente atrelados a programas e projetos de reformas macro econômicas estruturais ou setoriais. A função precípua desse tipo de cooperação é apoiar o país receptor com melhores condições socioeconômicas promovendo, subsidiariamente, o bem estar da população.

Esta modalidade abrange a maior parte de recursos envolvidos na cooperação para o desenvolvimento. Segundo Alonso; Fernandes (2005, p. 75) estima-se que ao menos $65 \%$ da Assistência Oficial ao Desenvolvimento (AOD) sejam constituídas das várias formas de cooperação financeira.

A Assistência Humanitária (AH) decorre de situação calamitosa e emergencial, que atinge às populações especialmente afetadas por catástrofes naturais ou provocada pela ação humana e em circunstância de calamidade pública, entre outras.

É um recurso pontual e de curto prazo voltado para a preservação da vida e mitigação de sofrimento de pessoas. Exemplo recente a ajuda prestada ao Haiti por quase toda a comunidade mundial após o terremoto que devastou aquele país em janeiro de 2010 .

A Cooperação Científica e Tecnológica (CC\&T) constitui-se na transferência específica de conhecimentos científicos e tecnológicos realizada entre dois ou mais interlocutores. Tem por escopo a implantação de projetos envolvendo o desenvolvimento de pesquisas conjuntas de interesse comum, abarcando o intercambio de especialistas. Pode não envolver diretamente entidades 
governamentais, mas instituições de pesquisa, centros e entidades de excelência investigativa (p.e., universidades) entre os países parceiros.

A CC\&T, dada a simetria e homogeneidade dos entes envolvidos, em geral não é caracterizada tradicionalmente como modalidade específica da cooperação para o desenvolvimento, subentendida, em alguns casos, como uma variante da cooperação técnica ${ }^{8}$.

A Ajuda Alimentar é a modalidade de cooperação para o desenvolvimento exercida sob a forma de remessa de alimentos para país ou região com situação crítica de insegurança alimentar ${ }^{9}$.

Tradicionalmente sua implementação ocorre por intermédio de organizações internacionais apoiadas pelo Programa Mundial de Alimentos ou por Organizações Não Governamentais.

Do ponto de vista conceitual, a Ajuda Alimentar não se confunde com Assistência Humanitária. Enquanto a $\mathrm{AH}$ atende a uma situação de curto prazo a Ajuda Alimentar possui um perfil de ação de cooperação para o desenvolvimento de longo prazo e de forma regular.

Quanto à Cooperação Técnica Internacional (CTI) o entendimento e conceituação têm evoluído ao longo do tempo.

Segundo LOPES (2005, p. 178), nos anos 1950 e 1960 a cooperação técnica foi formulada como um mecanismo de execução para transferência de tecnologia e aptidões humanas para países tomadores de empréstimo. Nos anos 1970 e 1980 a CT voltou-se a consequiências sustentáveis por meio de novas práticas inerentes a organizações formais. Em meados dos anos 1990 a CTI passou a ser vista como processo mais amplo formulado para criar e disseminar conhecimento humano com resultados esperados de desenvolvimento em todos os níveis da sociedade.

Nas pesquisas em busca de modelos conceituais sobre cooperação técnica, identificou-se a monografia de Helton Vargas Ferreira que assim conceitua a CTI:

"Atualmente o conceito de cooperação técnica internacional está intimamente ligado à noção de desenvolvimento e a ações de transferência de tecnologia e conhecimento (know-how), tendo como objetivo permitir que os países recebedores possam assimilar as inovações recebidas e reproduzi-las por conta própria. 
O termo cooperação técnica internacional subentende um intercâmbio externo dos países, sem conotação comercial, com a finalidade de intensificar e ampliar sua capacidade técnica para, de forma autônoma, conduzir e acelerar seus processos de desenvolvimento econômico e social" (FERREIRA, 2008, p. 21-22).

Em sua dissertação para obtenção do título de Mestre em Relações Internacionais, Luara Landulpho Alves Lopes, assim define a CTI:

"A cooperação técnica internacional trata, portanto, de projetos internacionais postos em execução por um ou mais Estados, com ou sem a participação de Organizações Internacionais, que têm como objetivo contribuir para o desenvolvimento dos países recebedores a partir do financiamento de atividades de capacitação técnica, que podem ser realizadas no país recebedor ou em forma de bolsa de estudo e treinamento no país doador" (LOPES, 2008, p. 24).

Numa abordagem subjacente, faculta-se inferir que Cooperação Técnica Internacional pode ser caracterizada como um conjunto de ações concertadas entre um país em desenvolvimento (recipiendário) e outro país, de forma bilateral, ou pelo intermédio de uma organização, de forma multilateral, que têm como objetivo o trabalho uníssono para execução de um projeto visando à disseminação associada à transferência, absorção e multiplicação de conhecimentos, de técnicas e de expertise, favorecendo o desenvolvimento de capacidades nas camadas individual, institucional e social para a consecução de um desenvolvimento sustentável e autóctone, tendo, em última análise, a sociedade como beneficiária.

A CTI, com maior ou menor ênfase, deve estar inserida na política externa do país. O objetivo deste estudo não é o de fazer comparações sobre a política externa e o tratamento dispensado à CTI. O que é relevante ao estudo é a contextualização da Cooperação Técnica Internacional dentro da Política Externa brasileira.

O tom que norteia a Política Externa do país vem, necessariamente, do mandatário da Nação e deve, desde o inicio, indicar claramente à diplomacia o caminho que deverá ser pavimentado no escopo das relações internacionais.

De acordo com a explicação do Prof. Doutor Henrique Altemani:

“... política externa é a área que representa os interesses e objetivos do Estado no plano internacional e que, por conseguinte, sua definição e implementação é prerrogativa do Estado" (ALTEMANI, 2005, p. 3). 
Nesta seara, uma das mais acentuadas tônicas sobre a ação do Brasil como agente 'exportador' de ações de cooperação técnica internacional, veio nos anos 1990 em discurso proferido pelo então Presidente Collor de Mello na XLV Sessão Ordinária da Assembléia Geral da Organização das Nações Unidas, realizada em setembro de 1990 .

No início do seu mandato (15/3/90 a 30/9/92) o ambiente interno era-lhe extremamente favorável, a despeito dos aspectos discutíveis do plano de combate à inflação, a sociedade brasileira, ansiosa pelas mudanças prometidas (principais eixos de campanha: combate à corrupção e controle definitivo da inflação), dava-lhe o beneplácito da expectativa positiva e da confiança.

No plano externo, o tema da modernização foi utilizado como alavanca para uma série de alterações de rumo destinadas a transpor a atuação diplomática brasileira da vertente dos países em desenvolvimento para uma busca de simetria com os países desenvolvidos. Nesse diapasão, alguns dos temas globais ${ }^{10}$ de interesse do Brasil evoluíram para atitudes mais transacionais de cooperação internacional. Pronunciou-se assim o Senhor Presidente da República Fernando Collor de Mello frente aos representantes dos países integrantes das Nações Unidas:

\footnotetext{
“A temática do desenvolvimento econômico e da cooperação internacional deve estar no topo da agenda multilateral

O Brasil quer desempenhar, em todas suas dimensões, o papel que the cabe na construção das estruturas mundiais de paz e cooperação

O que desejamos é um mundo de paz, cooperação, prosperidade, construída sobre os princípios maiores do direito internacional, onde se desenhe no horizonte de nossos povos o melhor destino que tanto esperam, merecem e hão de alcançar" (CORRÊA, Org, 2007, p. 525-529).
}

Com esse contundente discurso, a Agência Brasileira de Cooperação ganhou força política e impulsão na consolidação das suas atividades no curto espaço de Governo Collor.

Nos períodos de Governo do Presidente Fernando Henrique Cardoso (1/1/95 a 31/12/98 e de 1/1/99 a 31/12/02), no entanto, não houve significativas referências à cooperação técnica internacional nos discursos e manifestações presidenciais e dos chanceleres ${ }^{11}$. A matéria "cooperação internacional" quando eventualmente tratada 
ou presente em discursos possuía uma retórica pró-forma, atendendo ao oportunismo daquele momento.

A partir do Governo de Luiz Inácio Lula da Silva (1/1/03 a 31/12/06 e de 1/1/07 a 31/12/10) a cooperação técnica é focada como instrumento eficaz da política externa do governo, um ferramental condutor de ações que possa sustentar as metas da política exterior: fortalecimento do Mercosul, incremento das relações com América do Sul e África, amadurecimento das relações com os Estados Unidos, aproximação efetiva com os BRICs, participação dinâmica nos foros internacionais em especial os econômicos e, principalmente, na incessante busca pela conquista de assento no Conselho de Segurança das Nações Unidas, a principal prioridade da diplomacia do Governo Lula.

O braço executivo da posta em marcha da política de cooperação técnica do Governo Federal é a Agência Brasileira de Cooperação (ABC) do Ministério das Relações Exteriores (MRE), cujos pilares constitutivos estão calcados na definição, estruturação e operacionalização, da maneira mais satisfatória e produtiva possível, dos programas e projetos de cooperação técnica internacional desenvolvidos pelo Brasil sob as vertentes bilateral ou multilateral.

Criada pelo Decreto No 94.973, em setembro de 1987, a Agência Brasileira de Cooperação era parte integrante da estrutura da Fundação Alexandre de Gusmão (FUNAG), vinculada ao Ministério das Relações Exteriores (MRE).

Até então, as atividades de Cooperação Técnica eram compartidas entre a Secretaria de Planejamento da Presidência da República (SEPLAN) e o Ministério das Relações Exteriores. Aquela desempenhava as funções técnicas - prospecção, análise, validação e acompanhamento de projetos enquanto o Itamaraty se incumbia dos aspectos políticos da cooperação técnica internacional. Certamente, um modelo dual com conflitos de poder e de interesses.

Com a edição do Decreto 2070/96, a Agência Brasileira de Cooperação desvincula-se da FUNAG e passa compor a Secretaria-Geral do Ministério das Relações Exteriores. Em termos de atividades funcionais a $\mathrm{ABC}$ assume o papel único de coordenar, negociar, aprovar, acompanhar e avaliar, em âmbito nacional, a cooperação para o desenvolvimento em todas as áreas de conhecimento, tanto a 
recebida de outros países e organismos internacionais quanto à prestada pelo Brasil a outros países em desenvolvimento.

Cumpre à $\mathrm{ABC}$ atuar em estreita aliança com todos os órgãos que compõem a estrutura do Itamaraty, assim como interatuar ativamente com os órgãos setoriais do governo, com as instituições brasileiras envolvidas na proposição e na execução de projetos de cooperação técnica e perfazer as interações com os representantes de governos estrangeiros e de organismos internacionais.

Enquanto o Itamaraty é o vocal da política externa brasileira, a $\mathrm{ABC}$ é o órgão responsável pela operacionalização dos projetos de cooperação técnica internacional $^{12}$. 


\section{O SETOR POSTAL MUNDIAL E A COOPERAÇÃO TÉCNICA INTERNACIONAL}

A dimensão do "Setor Postal" é tão extensa quanto o é o nosso planeta. Sua composição é conformada por um amplo conjunto de stakeholders que, de forma direta ou indireta, é usuário ou beneficiário da prestação dos serviços postais ${ }^{13}$.

O Serviço Postal existe em todos os países. Em alguns, explorado de forma mais competitiva no segmento de mercado. Em outros, de forma mais tímida, cumprindo o papel essencialmente social a que se propõe. Em qualquer situação, o Serviço Postal é um fator de integração nacional e de conexão entre os povos, independente do regime de governo e das relações diplomáticas. A prestação do Serviço Postal é atribuída, em cada país, a um "operador postal designado", geralmente um ente estatal encarregado de cumprir a missão de correios no país. Dois alicerces caracterizam, assim, as atividades do operador oficial dos serviços postais: o de caráter social ${ }^{14}$ decorrente da vinculação à União Postal Universal e, muitas vezes, aos seus próprios preceitos constitucionais, e o de caráter comercial com atuação que transpassa aos serviços reservados - ou monopólio - atuando no campo concorrencial na disputa do mercado com a iniciativa privada.

No cenário do Século XXI, além dos operadores postais designados, ou seja, além dos "Correios" oficiais, são partícipes do Setor Postal mundial outros operadores que exercem atividades de correios de forma essencialmente comercial, característico da iniciativa privada. No Brasil, para exemplificação, citam-se grandes players internacionais com forte atuação interna como DHL, Federal Express, UPS e TNT.

No Quadro 1 - Atores do Setor Postal - reproduz-se a composição do Setor Postal sob a ótica da União Postal Universal. 


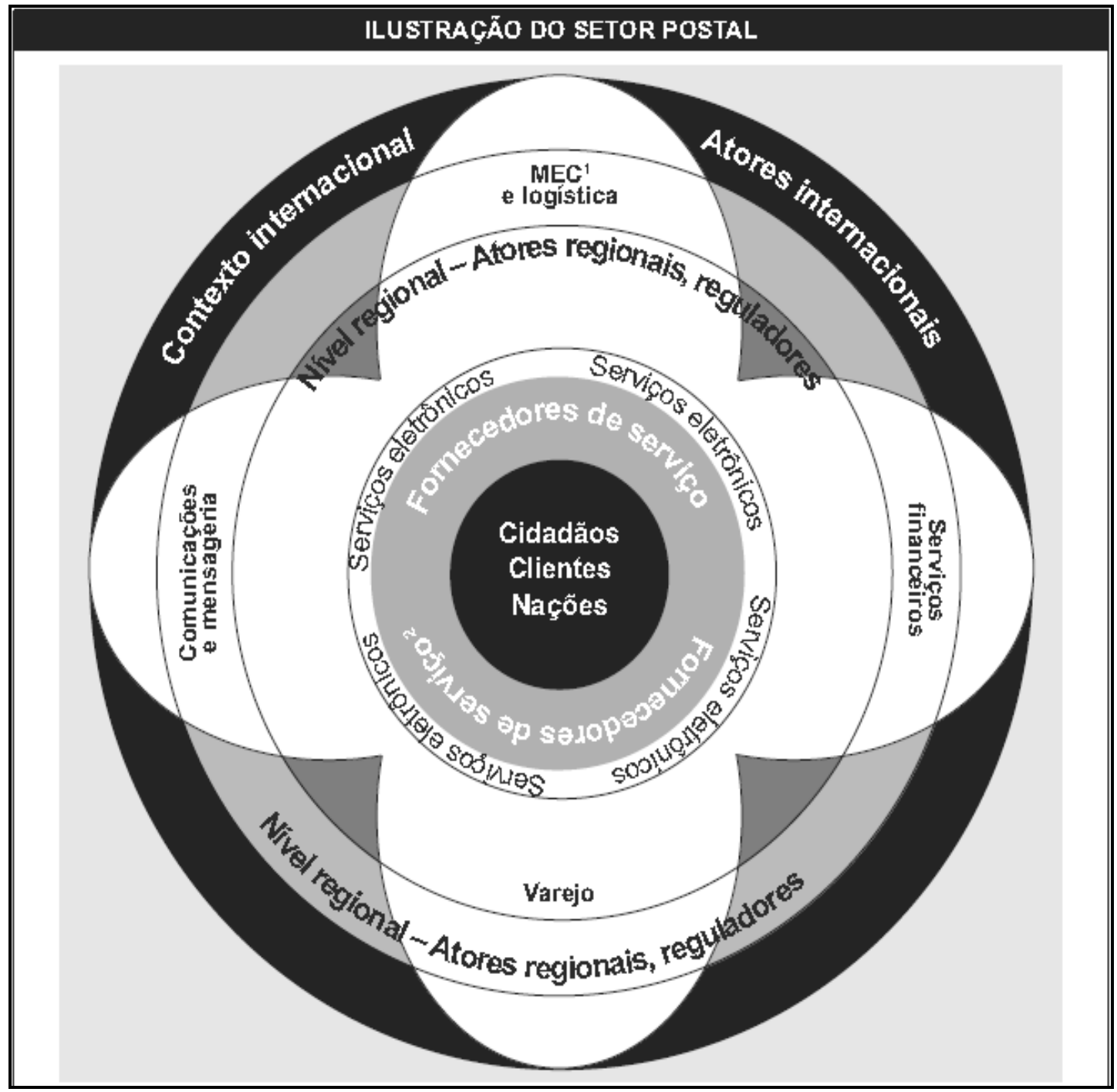

Quadro 1 - Atores do Setor Postal

Fonte: UPU, 2007

Legenda: 1 MEC = Mensageria, Expresso e Encomenda

2 Fornecedores de Serviços: Operadores Postais Designados e outros

Existente desde $1^{\circ}$ de julho de 1875 a União Postal Universal (UPU) congrega atualmente 191 países em torno do objetivo de formar um único território postal mundial.

Em fins do século XIX vários países organizaram-se na formação de 'associações' internacionais para estabelecerem regras que regulassem o desenvolvimento de atividades que transpunham suas fronteiras.

Em 1865, por exemplo, foi fundada a União Telegráfica Internacional - hoje existente como União Internacional de Telecomunicações (UIT) - e, em linha 
similar, em $1874^{15}$ iniciou-se a criação da UPU sendo oficialmente constituída em $1^{\circ}$ de julho de 1875 .

A UPU, com sede em Berna, Suíça é, hoje, uma instituição especializada da ONU compondo o quadro de Agências do Sistema das Nações Unidas. Na condição de organização intergovernamental é regida pelo direito público internacional e composta pelos Países-membros ${ }^{16}$.

É uma grande Organização responsável pela catalização de todos os países que interconectam uma rede postal mundial composta de 5.549.688 empregados, 657.391 agências postais, com a movimentação anual superior a 438 bilhões de cartas e mais de 6,5 bilhões de encomendas transitadas pelos correios dos 191 Paísesmembros, no ano de $2007^{17}$.

Na condição de Organização Internacional, a União Postal Universal é regida por uma constituição e tem assim conformada a sua estrutura funcional:

- O Congresso - órgão máximo da União. Integram o Congresso todos os países membros ${ }^{18}$. O Congresso realiza-se ordinariamente a cada quatro $\operatorname{anos}^{19}$ em solo de um dos países membros ${ }^{20}$.

- O Conselho de Operações (COP) - órgão formado por 40 Paísesmembros eleitos durante a Sessão do Congresso. Sua atividade tem foco nos operadores do sistema postal. O COP exerce as suas funções durante o período que separa dois Congressos sucessivos, reunindo-se anualmente para tratar das questões operacionais, econômicas e comerciais dos serviços postais (artigo 18 da Constituição e artigo 104 do Regulamento Geral).

- O Conselho de Administração (CA) - órgão formado por 41 Paísesmembros eleitos durante a Sessão do Congresso. Sua atividade tem foco nos reguladores (governos) do sistema postal. O CA reúne-se anualmente para assegurar a continuidade dos trabalhos da UPU entre os Congressos, supervisionar as atividades da União, examinar questões jurídicas, regulamentares, administrativas e financeiras e formular 
propostas relativas a estes temas (artigo 17 da Constituição e artigo 102 do Regulamento Geral).

- A Secretaria Internacional - órgão central, que funciona na sede ${ }^{21}$ da União sob a denominação de Secretaria Internacional da União Postal Universal, dirigida por um Diretor-Geral ${ }^{22}$, atua como órgão de execução, apoio, ligação, informação e de consulta para os paísesmembros (artigo 20 da Constituição e artigo 112 do Regulamento Geral).

Compete ao Diretor-Geral da UPU organizar, administrar e dirigir a Secretaria Internacional, da qual é o representante legal e serve de intermediário nas relações entre a União e as organizações internacionais. O Diretor Geral assegura as funções de depositário dos Atos da União e notifica todos os Governos dos Paísesmembros das decisões adotadas pelo Congresso.

A UPU tem como missão a coordenação da prestação dos serviços postais dos diferentes países membros, sem interferir nas políticas próprias dentro dos Estados. No Congresso da União Postal Universal de Viena, ocorrido em 1964, os Países-membros incorporaram à Constituição da UPU os princípios da cooperação técnica estabelecendo que "A União participa, dentro de suas possibilidades, da assistência técnica postal solicitada por seus Países-membros".

Em colaboração com o Programa das Nações Unidas para o Desenvolvimento (PNUD), a UPU coordena ações de cooperação técnica aos países menos avançados (PMA) e aos países em desenvolvimento (PED). Para tanto, conta com a expertise e o know-how de países mais desenvolvidos do ponto de vista postal para a implementação de programas de treinamento e de desenvolvimento dos recursos humanos, para a participação de consultores em projetos específicos de temas postais, bem como para o fornecimento de material de ponta e para assistência financeira em favor do desenvolvimento postal.

Atualmente a sua vocação está fortemente dirigida para o desenvolvimento e o apoio à cooperação técnica entre os Países-membros. 
No XXIV Congresso da União Postal Universal - Nairobi, ocorrido em 2008, os países signatários ratificaram para o quadrienio 2009 - 2012 a cooperação técnica como fator de apoio ao desenvolvimento.

A elaboração da Estratégia Postal de Nairobi (EPN), documento resultante dos trabalhos do Congresso e firmado pelos representantes plenipotenciários dos Estados integrantes da União Postal Universal, contemplou 4 objetivos associados a 18 programas estratégicos cujas ações a serem empreendidas pelos players que integram a comunidade postal (governos, órgãos reguladores, operadores postais designados e a própria UPU) visará dar respostas aos desafios específicos do Setor Postal em âmbito mundial.

Os pilares da Estratégia Postal de Nairobi são os seus objetivos que suportam três eixos: interconexão, desenvolvimento e governança e orbitam por três dimensões: física, eletrônica e financeira. A seguir são elencados os 4 objetivos definidos pela EPN para o quadriênio 2009 - 2012:

Objetivo 1: Melhorar a interoperabilidade, a qualidade e a eficácia da rede postal tridimensional, para que o setor postal possa continuar atender às necessidades do mercado e dos clientes ${ }^{23}$

Objetivo 2: Estimular um serviço postal universal adaptado ao contexto social, econômico e tecnológico ${ }^{24}$

Objetivo 3: Promover o desenvolvimento sustentável do setor postal e da sua economia ${ }^{25}$

Objetivo 4: Favorecer o crescimento dos mercados postais e dos serviços postais $^{26}$

No Anexo 1 é apresentado o quadro estrutural da Estratégia Postal de Nairobi.

No seu pronunciamento de apresentação da Estratégia Postal de Nairobi, o Diretor Geral da União Postal Universal, Edouard Dayan, tece o seguinte comentário sobre a arquitetura e o conteúdo da EPN, realçando a importância da cooperação técnica: 
"As discussões focaram a importância da reforma e da regulação do setor postal, o papel do setor como vetor de acesso às novas tecnologias, a capacidade do Correio em oferecer serviços eletrônicos de transferência de fundos, a importância da normalização e a necessidade de garantir a consideração das necessidades reais dos países, especialmente os países menos avançados, na cooperação ao desenvolvimento" (EPN, 2008, p. 5) [sem grifo no original].

Prossegue com lucidez e argumentação sem subsunção de caráter intervencionista:

\begin{abstract}
“Assim, a EPN reflete a determinação da UPU e de seus Países-membros em prosseguir com sua missão em prol de um desenvolvimento duradouro dos serviços postais, justificando a necessidade de sua ação em um mundo que se globaliza. Em um contexto como este, apenas uma ação multilateral conjunta pode fornecer as respostas adaptadas. A rede postal e suas três dimensões - física, eletrônica e financeira - devem poder adaptar-se a um contexto em plena mutação, exigido que também tenhamos em mente nossos valores, tendo a preocupação constante de sempre servir da melhor forma os Países-membros, bem como os usuários de serviços postais em todo o mundo, seja particulares ou empresas. (EPN, 2008, p. 6)" [sem grifo no original].
\end{abstract}

A União Postal Universal tem por missão estimular e apoiar ações para desenvolvimento do serviço postal universal, de forma sustentável, com qualidade, eficiência e acessibilidade a fim de viabilizar a comunicação e o comércio entre os cidadãos do planeta, garantindo, essencialmente, a cooperação, a interação e o aprimoramento dos serviços e das relações entre os Países-membros, promovendo uma cooperação técnica eficaz.

A cooperação ao desenvolvimento no âmbito da UPU é um dos principais sustentáculos dessa missão. Além de ser do interesse de todos os Países-membros da União, a cooperação consiste na implementação de programas conexos, proporcionando maior proximidade e favorecendo a mitigação do gap postal entre os países industrializados (PI) e os países em desenvolvimento (PED), com especial atenção para os países menos avançados (PMA), por meio de alianças bilaterais e multilaterais. A cooperação técnica no Setor Postal constitui-se instrumento chave para o alcance dos objetivos estratégicos da UPU. 


\section{O SETOR POSTAL NO BRASIL, A EMPRESA BRASILEIRA DE CORREIOS E TELÉGRAFOS E A INSERÇÃO INTERNACIONAL}

Num país de 8,5 milhões de $\mathrm{Km}^{2}$, composto de 5.564 municípios, com várias assimetrias (desenvolvimento, industrialização, Índice de Desenvolvimento Humano (IDH), populacionais, econômicas dentre diversos indicadores) a prestação dos serviços postais sempre se constitui em um grande desafio para o Governo.

A história dos serviços postais brasileiros se confunde com a própria história do Brasil. De uma forma simbólica pode-se dizer que correios no Brasil existem desde o descobrimento. Ao ser descoberto, em 22 de abril de 1500, o Brasil (então Ilha de Vera Cruz) foi relatado pelo escrivão-mor que integrava a tripulação comandada por Pedro Álvares Cabral, Pero Vaz de Caminha, numa extensa carta dirigida ao Rei de Portugal, considerada certidão de nascimento do Brasil, explanando sobre as terras recém descobertas ${ }^{27}$.

Com o inicio da colonização e a necessidade de comunicação de/para Colônia, a Coroa portuguesa em 1673 criou oficialmente o Correio-Mor das Cartas do Mar que a partir de 1798 sofreu uma espécie de reestruturação e passou a denominar-se Correios Marítimos, com a expansão dos serviços ao interior da Colônia ${ }^{28}$.

Com a Chegada da Família Real, em 1808, foi dado novo impulso ao desenvolvimento do serviço postal. Nessa época foi criado o primeiro Regulamento Postal do Brasil e a emissão de decretos criando vários correios interiores. Em 1843 o Brasil lançou seu primeiro selo, a famosa série "Olho-de-boi”. Foi o segundo país do mundo a emitir selos ${ }^{29}$.

No ano de 1887 o Brasil adere ao Tratado que criou a União Geral dos Correios que posteriormente passou a ser denominada União Postal Universal (1879).

A Revolução de 1930 provocou uma densa reforma na estrutura políticoadministrativa do Brasil, extensiva às atividades postais. Por Decreto, o então Presidente da República, Getúlio Vargas, funde a Direção-Geral dos Correios com a 
Repartição-Geral dos Telégrafos, criando dessa forma o Departamento de Correios e Telégrafos (DCT) pertencente ao Ministério de Viação e Obras Públicas.

Em 20 de março de 1969, o então Presidente da República, Costa e Silva sob a égide do AI-5 - firmou o Decreto-Lei 509 extinguindo o DCT e criando a Empresa Brasileira de Correios e Telégrafos (ECT) vinculada ao Ministério das Comunicações (MC).

Atualmente, a ECT é o Operador Postal Designado pelo Estado responsável pelo cumprimento do serviço postal universal no Brasil e representante oficial do país nos fóruns e Organizações postais internacionais. Os acordos e tratados entre o Brasil e OIs ou entre o Brasil e outros países no âmbito do Setor Postal, são cumpridos pela Empresa Brasileira de Correios e Telégrafos.

Contudo, não é a ECT o único ator no cenário do Setor Postal brasileiro, concorrendo com diversos players. Em grandes centros, como São Paulo e Rio de Janeiro, identificou-se mais de 12 mil empresas nacionais e algumas multinacionais voltadas para a prestação de serviços postais.

Na ausência de uma Agência Reguladora o Ministério das Comunicações exerce o papel de norteador no desenvolvimento do Setor Postal brasileiro, ainda que timidamente, uma vez que do ponto de vista legal não lhe é atribuída a competência de órgão regulador.

Neste campo fértil de prestação de serviços postais, uma questão por muito tempo permeia as discussões dos atores do Setor: a recepção do monopólio postal pela Constituição Federal de 1988.

O assunto, há anos discutido nos tribunais, chegou à esfera do Supremo Tribunal Federal. Aquela egrégia Corte decidiu pela manutenção do monopólio de correspondências em favor do Estado. Em última análise, caberá à Empresa Brasileira de Correios e Telégrafos honrar pelo cumprimento da decisão, não podendo furtar-se de atender à demanda da sociedade no recebimento e entrega das correspondências sob reserva do Estado ${ }^{30}$.

A ECT é uma Empresa Pública, de direito privado, que possui $100 \%$ do seu capital integralizado pela União. Sua estrutura está alicerçada por uma 
Administração Central e por 28 Diretorias Regionais. Tem como Missão "Fornecer soluções acessíveis e confiáveis para conectar pessoas, instituições e negócios, no Brasil e no mundo", a Visão estabelecida é a de "Ser uma empresa de classe mundial", ao passo que direciona seu Negócio para "Soluções que aproximam" e cultiva seus Valores na "Ética, Meritocracia, Respeito às Pessoas, Compromisso com o Cliente e Sustentabilidade".

A estatal é comandada por uma Diretoria Colegiada composta por um Presidente e seis Diretores de Áreas (Administração, Comercial, EconômicoFinanceira, Gestão de Pessoas, Operações e Tecnologia e Infra-estrutura) e reporta-se ao Conselho de Administração. No anexo 2 apresentamos o organograma atual da Empresa Brasileira de Correios e Telégrafos.

Presente em cada município brasileiro, a ECT tem uma capilaridade formada por uma rede de 6.186 agências próprias e 6.150 agências terceirizadas, 16 Centros de Tratamento de Cartas, 13 Centros de Tratamento de Encomendas, 25 Centros de Tratamento de Cartas e Encomendas e 2 Centros de Tratamento de Correio Internacional. Na área de distribuição (carteiros) dispõe de 905 Centros de Distribuição Domiciliária, 111 Centros de Entrega de Encomendas e outras 6.702 unidades de distribuição. Possui ainda 7 Centros de Serviços Telemáticos, 40 Centros de Transporte Operacional, 16 Centros de Logística Integrada, 7 Terminais de Carga Aérea e uma Rede Postal Aérea Noturna (RPN) composta por 15 aeronaves fretadas $^{31}$.

A ECT é uma Empresa cujos processos são fortemente caracterizados por atividades humanas. 108.614 empregados regidos pela Consolidação das Leis do Trabalho (CLT) integram o seu Quadro de Pessoal. 86\% exercem atividades nas áreas fins da instituição e 14\% formam o overhead. 51,8\% dos empregados da ECT são carteiros. Do total de empregados, cerca de 5\% possuem nível de escolaridade fundamental, quase $78 \%$ nível médio e pouco mais de $17 \%$ possuem nível escolar superior $^{32}$. A ECT possui também 1.876 pessoas em programas sociais ${ }^{33}$.

O volume estimado em 2009 de correspondências movimentadas pela ECT foi na ordem de 6,1 bilhões de objetos. $\mathrm{Na}$ área de encomendas cujo mercado é aberto à concorrência por não estar sob o manto do monopólio, a ECT recepcionou, 
no mesmo período, cerca de 171 milhões de envios e recebeu 46 milhões de objetos procedentes do exterior, perfazendo junto com os demais serviços prestados (impressos, mala direta, etc.), um montante de 8,1 bilhões de itens distribuídos ${ }^{34}$ nos 55 milhões de domicílios brasileiros ${ }^{35}$.

Os números dos Correios do Brasil demonstram a grandiosidade da Estatal. Os resultados qualitativos que apresenta, a confiabilidade da população na Empresa observada em pesquisas independentes e a ativa participação nos fóruns, congressos e grupos de trabalho em que a ECT participa na União Postal Universal e em outras Organizações Internacionais, a fazem ser mundialmente respeitada. Nos quadros da UPU, em março de 2010, encontravam-se cedidos 7 empregados de carreira da ECT.

Para melhor visualização comparativa, apresentamos o Quadro 2 Estatística Postal Mundial Comparada, cujos levantamentos foram coordenados pela União Postal Universal. Convém esclarecer que a pesquisa da UPU tem por base dados relativos ao ano calendário de 2008.

Em linhas gerais os principais resultados do Correio brasileiro em comparação com seus pares são apresentados a seguir:

\begin{tabular}{|c|c|c|}
\hline ESTATÍSTICAS & CORREIO BRASILEIRO & $\begin{array}{l}\text { PRINCIPAIS } \\
\text { RESULTADOS }\end{array}$ \\
\hline Volume de correspondências & $\begin{array}{l}\text { Distribuiu o } 6^{\circ} \text { maior volume } \\
\text { de correspondência do mundo. }\end{array}$ & $\begin{array}{l}1^{\circ} \text { Eua } \\
2^{\circ} \text { Alemanha } \\
3^{\circ} \text { Grã-Bretanha } \\
4^{\circ} \text { França }\end{array}$ \\
\hline $\begin{array}{l}\text { Receitas Operacionais } \\
\text { (Direito Especial de Saque) }\end{array}$ & $\begin{array}{l}9^{\mathrm{a}} / 10^{\circ} \text { maior receita operacional } \\
\text { do mundo }\end{array}$ & $\begin{array}{l}1^{\circ} \text { Alemanha } \\
2^{\circ} \text { Eua } \\
3^{\circ} \text { França } \\
4^{\text {o Japão }} \\
5^{\circ} \text { Grã-Bretanha } \\
6^{\circ} \text { Itália } \\
\text { Dados do Correio da China } \\
\text { não estão disponíveis. }\end{array}$ \\
\hline $\begin{array}{l}\text { Receitas Operacionais/ } \\
\text { habitante. } \\
\text { (Algo como o quanto cada } \\
\text { habitante gasta com os } \\
\text { serviços postais). }\end{array}$ & $43^{\mathrm{a}}$ & $\begin{array}{l}1^{\circ} \text { Suíça } \\
2^{\circ} \text { Nova Caledônia } \\
3^{\circ} \text { Alemanha } \\
4^{\mathrm{o}} \text { França } \\
5^{\mathrm{o}} \text { Finlândia } \\
\end{array}$ \\
\hline $\begin{array}{l}\text { Produtividade R/D } \\
\text { (Receita/Despesa) }\end{array}$ & $28^{\circ}$ posição & $\begin{array}{l}1^{\circ} \text { Polinésia Francesa } \\
2^{\circ} \text { Botswana } \\
3^{\circ} \text { Ruanda } \\
4^{\circ} \text { Vanuatu }\end{array}$ \\
\hline
\end{tabular}




\begin{tabular}{|c|c|c|}
\hline ESTATÍSTICAS & CORREIO BRASILEIRO & PRINCIPAIS RESULTADOS \\
\hline 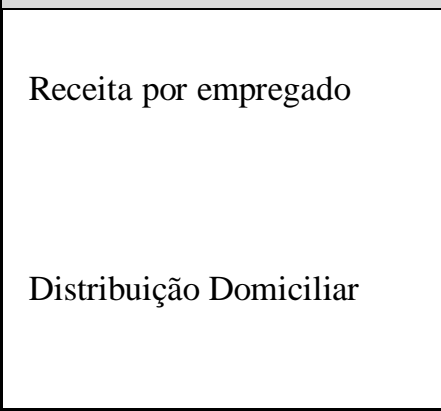 & $79 \%$ & $\begin{array}{l}1^{\circ} \text { Suécia } \\
2^{\circ} \text { Alemanha } \\
3^{\circ} \text { Áustria } \\
4^{\circ} \text { França } \\
32 \text { países } 100 \% \\
39 \text { países de } 99,95 \text { a } 90 \% \text { da } \\
\text { população } \\
\text { Eua } 89,6 \% \text {; Austrália } 99,5 \% \\
\text { Índia } 100 \% \text {; Rússia: dados não } \\
\text { disponíveis }\end{array}$ \\
\hline $\begin{array}{l}\text { Número médio de objetos } \\
\text { postado por habitante }\end{array}$ & 42 objetos & $\begin{array}{l}1^{\circ} \text { Vaticano } 6.688,77 \\
2^{\circ} \text { Suíça } 700,867 \\
3^{\circ} \text { Eua } 620,71 \\
\end{array}$ \\
\hline Número de Agências Postais & $8^{\circ}$ com 12.352 agências & $\begin{array}{l}1^{\circ} \text { Índia } 155.035 \\
2^{\circ} \text { China } 57.829 \\
3^{\circ} \text { Rússia } 40.482 \\
4^{\circ} \text { Eua } 36.723\end{array}$ \\
\hline $\begin{array}{l}\text { Quantidade de Centros de } \\
\text { Triagem }\end{array}$ & $9^{\circ}$ lugar com 56 centros & $\begin{array}{l}1^{\circ} \text { Grã-Bretanha } 805 \\
2^{\circ} \text { Eua } 614 \\
3^{\circ} \text { Índia } 416 \\
4^{\circ} \text { China } 201 \\
\end{array}$ \\
\hline Número de empregados & $10^{\circ}$ lugar & $\begin{array}{l}1^{\circ} \text { China } \\
2^{\circ} \text { Eua } \\
3^{\circ} \text { Alemanha } \\
4^{\circ} \text { Rússia }\end{array}$ \\
\hline
\end{tabular}

Quadro 2 - Estatística Postal Mundial Comparada

Fonte: ECT - Departamento de Planejamento Estratégico: Artigo Horizontes Estratégicos "Correios Comparados: Edição 2010 publicado em 19/03/2010.

Pela primeira vez, a UPU divulgou a percentagem de carteiros em relação ao número total de empregados dos Correios. O Brasil figurou em $16^{\circ}$ lugar com $50,49 \%$ (ano de 2008) ${ }^{36}$. A maior percentagem é a do Correio da Grã-Bretanha $89,30 \%$ e Botswana 82,04\%. O segmento de correspondência (que no Brasil e em grande parte dos países está sujeito ao monopólio) representa menos de 50\% das receitas operacionais da maioria dos Correios no mundo. 


\section{PERFORMANCE DA ECT COMO AGENTE DA POLÍTICA DE COOPERAÇÃO INTERNACIONAL DO BRASIL}

O Brasil como País-membro da UPU e signatário das Atas aprovadas nos Congressos é constantemente instado a participar de ações de cooperação técnica por aquela Organização Internacional.

No Congresso de Bucareste (2004) os representantes plenipotenciários dos Países-membros aprovaram a Estratégia Postal Mundial de Bucareste (EPMB) que incluía a implantação do Plano Integral de Reforma e Desenvolvimento Postal (PIDEP) nos países em desenvolvimento (PED).

Em síntese, o PIDEP é uma metodologia de apoio aos Governos dos Paísesmembros para desenvolver o Setor Postal. Esse desenvolvimento está atrelado ao cumprimento de 4 fases do PIDEP: a definição, abrangência e delimitações do Serviço Postal Universal, a revisão ou, na maior parte dos casos, a definição de uma Política Setorial no âmbito postal, uma revisão do Marco Legal para adaptação jurídica capaz permitir a implantação da política definida e, por fim, a modernização do Operador Postal Designado para que possa fazer frente ao mercado com competitividade e sustentabilidade. Para obter informação mais aprofundada sobre o PIDEP recomenda-se consulta ao site www.correios.com.br/pidep.

O Brasil, no período 2005-2009, respondeu favoravelmente às demandas da UPU. Sediou, na Universidade Correios, o primeiro curso mundial de formação para certificar consultores em formulação de PIDEP do qual participaram 15 profissionais estrangeiros selecionados pela UPU e 12 profissionais recrutados nacionalmente e, posteriormente, a ECT participou, com a cessão de consultores, na elaboração/implantação do PIDEP em 7 dos 12 países latino americanos onde o PIDEP foi formulado e mais um na região do Caribe (São Cristóvão e Neves).

No anexo 3 apresentamos o quadro oficial fornecido pela UPU com o panorama dos países onde houve a formulação do PIDEP e a indicação daqueles que o Brasil participou.

No mesmo período a ECT participou de 9 iniciativas de ações de cooperação técnica demandadas pela Agência Brasileira de Cooperação do 
Ministério das Relações Exteriores e de 12 ações de cooperação demandadas pelo Ministério das Comunicações, especificamente para o projeto "Exportações por Remessas Postais".

No âmbito bilateral, não obstante a ECT haver firmado 20 Protocolos de Intenção com outros países, foram desenvolvidas oito ações de cooperação com apenas 5 países, no período de 1997 a 2005.

No espeque da cooperação multilateral, a Empresa Brasileira de Correios e Telégrafos atuou como agente propulsor da cooperação técnica internacional em 58 eventos coordenados por Organizações Internacionais, com ênfase para a União Postal Universal, entre 1995 e 2009.

Por fim, ainda como agente de cooperação técnica, a ECT patrocinou a realização de 23 atividades de capacitação em solo brasileiro favorecendo o aperfeiçoamento de profissionais de mais de 40 países, entre 1995 e 2009. Acrescente-se que nestas atividades estão contempladas as formações de profissionais no Curso de Administração Postal, com 2 anos de duração.

No anexo 4 encontra-se a lista das ações de cooperação técnica internacional prestadas pela Empresa Brasileira de Correios e Telégrafos no período de 1995 a 2009.

A quantidade de ações de cooperação técnica em que houve participação da ECT num primeiro momento pode parecer relevante, porém, quando diluída ao longo do período estudado (1995 - 2009), demonstra acanhamento para uma Empresa do porte, do conhecimento e da influência que a instituição exerce no Setor Postal Internacional.

A Constituição da República Federativa do Brasil prevê no Art. 4, inciso IX, in litteris:

Art. 4 - A República Federativa do Brasil rege-se nas suas relações internacionais pelos seguintes princípios:

(...)

IX - cooperação entre os povos para o progresso da humanidade; 
A ECT, na senda de longa manus do Governo deve atender às políticas governamentais e ser partícipe na cooperação técnica no âmbito de sua competência e habilidade.

Até a conclusão deste trabalho (março de 2010), a ECT não possuía Plano Estratégico. Navegava sobre a versão revisada do Plano Estratégico 2004-2007/2008 adotado para o exercício de 2009. Mesmo assim, nele não há previsão, nem metas, nem uma estratégia definida para as atividades de cooperação técnica não obstante as diretrizes e os chamamentos governamentais ${ }^{37}$.

O último Relatório Empresarial e Social da $\mathrm{ECT}^{38}$, referente ao exercício 2008, faz um balanço dos resultados e apresenta a seguinte mensagem da Diretoria:

\footnotetext{
"Mesmo com o conturbado cenário financeiro das corporações pelo mundo, a Empresa Brasileira de Correios e Telégrafos (ECT) encerrou 2008 com excelentes resultados, destacando-se entre as principais empresas públicas brasileiras. $\mathrm{O}$ faturamento, de $\mathrm{R} \$ 11$ bilhões, é recorde na história da Empresa e representa um aumento de $13 \%$ na receita operacional. Quanto ao lucro total, o ganho da Empresa foi um dos maiores da sua história, girando em torno de $\mathrm{R} \$ 800$ milhões. Essa é a segunda vez consecutiva, no período de sete anos, que o negócio postal obtém resultado positivo, cujo montante, em 2008, foi da ordem de R\$120 milhões" (Relatório Empresarial, 2008, p. 3).
}

Com foco nos resultados financeiros obtidos naquele exercício, olvida-se, em todo o informe, de mencionar as ações internacionais de cooperação técnica. Indispõe a ECT de uma política interna para a cooperação, navega, neste oceano, sem ao menos uma bússola desprezando a sua potencialidade e não associando a energia despendida e know-how transferido à metas e resultados.

Uma vez que não exista uma política interna, inexistem metas e, portanto, não há o que se falar em indicadores, em desempenhos e menos ainda em resultados esperados.

Os resultados da cooperação técnica prestada pela ECT, a despeito dos acordos internacionais firmados e da política governamental vigente, são meramente administrativos, sem avaliação da efetividade dessas ações e também não estão associados a projetos e programas que contribuam para o desempenho institucional e tampouco possuem aderência à Identidade Corporativa da Empresa. 
Em sua dissertação para obtenção de título de Mestre em Relações Internacionais, Osório Carvalho Dias resume, de forma perspicaz, em sua conclusão:

A cooperação técnica internacional constitui importante instrumento de desenvolvimento, auxiliando um país a promover mudanças estruturais nos seus sistemas produtivos, como forma de superar restrições que tolhem seu natural crescimento. Os programas implementados sob sua égide permitem transferir conhecimentos, experiências de sucesso e sofisticados equipamentos, contribuindo assim para capacitar recursos humanos e fortalecer instituições do país receptor, a possibilitar-lhe salto qualitativo de caráter duradouro (DIAS, 2007, p. 69)

Não obstante a ausência de planejamento interno estruturado é inconteste a importância da cooperação técnica prestada pela ECT para o fomento ao desenvolvimento sustentável do Setor Postal mundial em que está inserida, com especial atenção à Região Latino-americana. 


\section{CONCLUSÃO}

A Empresa Brasileira de Correios e Telégrafos é uma instituição pública com elevado grau de respeitabilidade por parte da sociedade brasileira e de reconhecida competência pela comunidade internacional no universo do Setor Postal.

Esta conquista de credibilidade traz à responsabilidade a superação dos desafios que se apresentam para o século XXI: atendimento às necessidades dos clientes, manter-se competitiva num mercado cada vez mais aberto e pujante, ter custos racionais e qualidade de serviços elevada e, sem deslembrar do seu papel social, chegar aos mais longínquos rincões do país para oferecer o serviço postal universal. Concertar o desafio empresarial com a necessidade social passando pela capacitação, reconhecimento e valorização da sua força de trabalho é um grande desafio que somente será superado com o profissionalismo, com a ética e com o cumprimento aos princípios gerais da administração.

Este trabalho procurou responder a uma pergunta aparentemente simples: é a ECT um agente de Governo para a cooperação técnica internacional prestada? Necessário se fez estudar o contexto internacional. O que é a cooperação técnica, como surgiu, como o Brasil a vê e como participa nessas ações. Procurou-se avaliar o papel da diplomacia brasileira e a proposta autônoma e desinteressada conduzida pelo Ministério das Relações Exteriores.

Uma vez compreendidas as funções da cooperação técnica e a política de Governo, estudou-se o ambiente do Setor Postal. Compõe o estudo a identificação do que é o Setor Postal, quem são os atores e suas funções e identificou-se que a União Postal Universal é o grande orquestrador dos temas postais, transformando o mundo num território postal único. É, ainda, esta Organização a grande coordenadora de ações de cooperação técnica sobre o tema postal. Desenvolve projetos, atua junto a Governos, estabelece objetivos estratégicos, atrai os países industrializados a apoiar os países menos avançados e apresenta resultados nos Conselhos e no Congresso.

Delimitados os contornos do Setor Postal mundial, chegamos à realidade brasileira. O estudo então identifica o Setor Postal nacional e o seu ator mais representativo, o operador postal designado que é a Empresa Brasileira de Correios e 
Telégrafos. Diferentes dados da Empresa assim como o seu histórico adensam a propriedade de que a ECT tem a competência requerida para atuar como agente de cooperação técnica, dando suporte ao país para o cumprimento de um mandato constitucional no âmbito das relações internacionais.

Os números apresentados pelo estudo demonstram diversas ações de cooperação técnica prestada e permitem classificar a ECT como instituição com enorme potencial para contribuir de forma substantiva no apoio ao Governo para o cumprimento das políticas de relações exteriores com foco na agenda de cooperação técnica.

Como conclusão, pode-se dizer que, ainda que se associe o conhecimento e preparação de profissionais, inclusive certificados internacionalmente, ao know-how sobre a metodologia de prestação de cooperação técnica, se não houver uma estratégia da ECT voltada para a construção de uma política pragmática e assertiva de relações internacionais, a Empresa carregará a potencialidade de ser um contribuinte e um partícipe da política externa sem se caracterizar efetivamente como um agente governamental nas ações de cooperação técnica. 


\section{REFERÊNCIAS}

ALONSO, M.M.; FERNANDES, A.P. ABCD: Introdução à Cooperação para o Desenvolvimento. Lisboa: Colprinter, 2005.

ALtemani, Henrique. Política Externa Brasileira. São Paulo: Saraiva, 2005. 291p.

ALTEMANI, Henrique; LESSA, Antônio Carlos. Política Internacional Contemporânea: mundo em transformação. São Paulo: Saraiva, 2006.

ALTEMANI, Henrique; LESSA, Antônio Carlos (Org.). Relações Internacionais no Brasil: temas e agendas, v.1. São Paulo: Saraiva, 2006.

ALTEMANI, Henrique; LESSA, Antônio Carlos (Org.). Relações Internacionais no Brasil: temas e agendas, v.2. São Paulo: Saraiva, 2006.

ARAÚJO, Ernesto Henrique Fraga. O Mercosul: negociações extra-regionais. Brasília: Fundação Alexandre de Gusmão, 2007. 352p.

ARRAES, Virgilio. Relações Internacionais: o desgaste da nova ordem mundial. Brasília: Universa, 2008. 218p.

CERVO, Amado Luiz. Socializando o Desenvolvimento: uma história da cooperação técnica internacional do Brasil. Revista Brasileira de Política Internacional 37 (1): 1994.

CERVO, Amado Luiz. Inserção Internacional: formação dos conceitos brasileiros. São Paulo: Saraiva, 2008. 297p.

CORRÊA, Luiz Felipe de Seixas (Org.). O Brasil nas Nações Unidas. Brasília: Fundação Alexandre de Gusmão, 2007. 768p.

DIAS, Osório Carvalho. Conceitos de cooperação técnica internacional e a cooperação técnica internacional postal. 2007. 76p. Dissertação (Mestrado) Instituto de Relações Internacionais da Universidade de Brasília. Brasilia, 2007.

FERREIRA, Helton Vargas. A Cooperação Técnica Internacional e a Difusão Tecnológica no Brasil. 2008. 37p. Monografia. Centro Universitário de Brasília (UniCEUB/ICPD). Brasília, 2008. 
FONTOURA, Roberto Campos Tarrisse da. O Brasil e as Operações de Manutenção da Paz das Nações Unidas. Brasília: Fundação Alexandre de Gusmão, 1999. 448p.

JACKSON, Robert; SORENSEN, Georg. Introdução às Relações Internacionais. Rio de Janeiro: Jorge Zahar Ed., 2007.

LESSA, Antônio Carlos. História das Relações Internacionais: a pax britannica e o mundo do século XIX. Petrópolis, RJ: Vozes, 2008. 167p.

LOPES, Carlos. Cooperação e Desenvolvimento Humano: a agenda emergente para o novo milênio. São Paulo: UNESP, 2005.

LOPES, Luara Landulpho Alves. Cooperação Técnica entre Países em Desenvolvimento (CTPD) da Agência Brasileira de Cooperação (ABC-MRE): o Brasil como doador. 2008. 164p. Dissertação (Mestrado). San Tiago Dantas (UNICAMP e PUC-SP)

MACHADO, Fernando Vieira. Cooperação Técnica entre Países em Desenvolvimento: o Brasil e os países da América Latina. Dissertação (Mestrado). Universidade de Brasília. Brasília, 2004.

NAIROBI POSTAL STRATEGIC, 2008, http://www.upu.int/congress/en/2008 congress nairobi postal strategy en.pdf, acesso em 16/02/2010

POLITICA EXTRIOR. Madrid: Editora Estúdios de Política Exterior, Edición Septiembre/Octubre, n. 131. 170p. 2009.

SARAIVA, José Flávio Sombra (Org.). História das Relações Internacionais Contemporâneas: da sociedade internacional do século XIX à era da globalização. São Paulo: Saraiva, 2008.

WILBERT, Julieta Kaoru Watanabe. Referenciais Comparativos para Indicadores de Desempenho utilizados no Setor Postal Brasileiro: Uma contribuição ao processo de busca de excelência em gestão da ECT. 2008. 76p. Trabalho de Conclusão de Curso. Faculdade de Tecnologia do SENAI Florianópolis. Curso de Pós-Graduação MBA Gestão para Excelência. Defendida em 15/12/2008. 


\begin{abstract}
ANEXOS
ANEXO 1 - QUADRO ESTRUTURAL DA ESTRATÉGIA POSTAL DE NAIROBI.

ANEXO 2 - ORGANOGRAMA DA EMPRESA BRASILEIRA DE CORREIOS E TELÉGRAFOS

ANEXO 3 - RELAÇÃO DOS PAÍSES ONDE HOUVE A FORMULAÇÃO DO PIDEP

ANEXO 4 - RELAÇÃO DAS AÇÕES DE COOPERAÇÃO TÉCNICA INTERNACIONAL PRESTADAS PELA EMPRESA BRASILEIRA DE CORREIOS E TELÉGRAFOS NO PERÍODO DE 1995 A 2009
\end{abstract}




\section{ANEXO 1 - QUADRO ESTRUTURAL DA ESTRATÉGIA POSTAL DE NAIROBI}

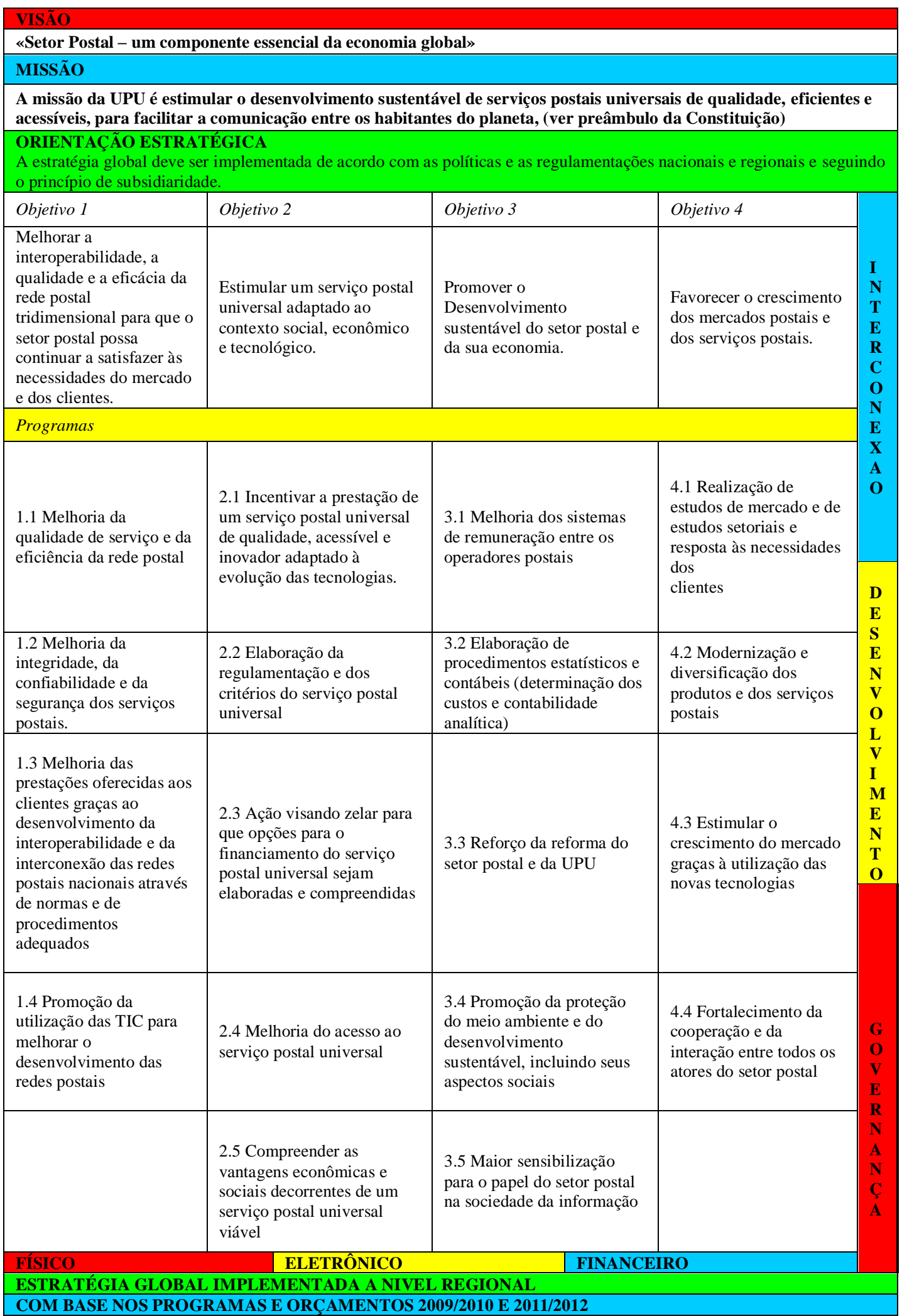




\section{ANEXO 2 - ORGANOGRAMA DA EMPRESA BRASILEIRA DE CORREIOS E TELÉGRAFOS}

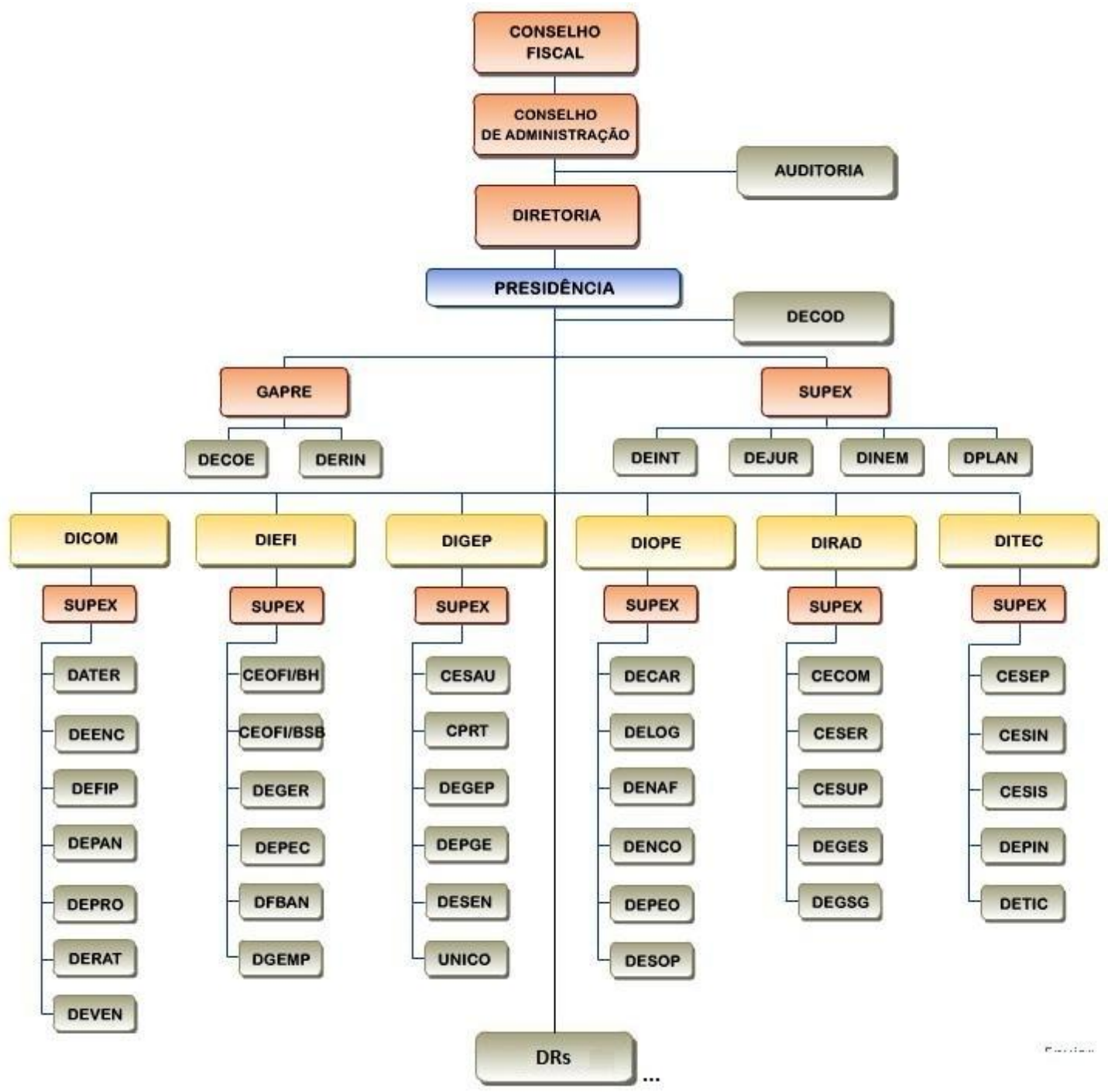

Fonte: Empresa Brasileira de Correios e Telégrafos 


\section{ANEXO 3 - RELAÇÃO DOS PAÍSES ONDE HOUVE A FORMULAÇÃO DO PIDEP}

\section{LISTE DES PIDEP RÉALISÉS}

\begin{tabular}{|c|c|c|c|c|c|c|}
\hline & Afrique & Pays arabes & Amérique latine & $\begin{array}{l}\text { Asie/ } \\
\text { Pacifique }\end{array}$ & Caraïbes & $\begin{array}{l}\text { Europe } \\
\text { et CEI }\end{array}$ \\
\hline \multicolumn{7}{|c|}{2005} \\
\hline Pays & $\begin{array}{l}\text { Gambie } \\
\text { Mali } \\
\text { Tchad }\end{array}$ & $\begin{array}{l}\text { Kuwait } \\
\text { Syrienne } \\
\text { (Rép. arabe) }\end{array}$ & $\begin{array}{l}\text { Costa-Rica } \\
\text { Panama (Rép.) } \\
\text { Paraguay }\end{array}$ & $\begin{array}{l}\text { Bhoutan } \\
\text { Lao (Rép. } \\
\text { dém. pop.) } \\
\text { Népal } \\
\text { Sri Lanka }\end{array}$ & $\begin{array}{l}\text { Bahamas } \\
\text { Belize } \\
\text { Jamaïque }\end{array}$ & $\begin{array}{l}\text { Ex-Rép. } \\
\text { yougosla } \\
\text { ve de } \\
\text { Macédoin } \\
\text { e }\end{array}$ \\
\hline $\begin{array}{l}\text { Total } \\
2005\end{array}$ & 3 & 2 & 3 & 4 & 3 & 1 \\
\hline \multicolumn{7}{|c|}{2006} \\
\hline Pays & $\begin{array}{l}\text { Bénin } \\
\text { Burundi } \\
\text { Comores } \\
\text { Lesotho } \\
\text { Seychelles }\end{array}$ & $\begin{array}{l}\text { Djibouti } \\
\text { Egypte } \\
\text { Soudan } \\
\text { Yémen }\end{array}$ & $\begin{array}{l}\text { Colombie } \\
\text { Uruguay }\end{array}$ & $\begin{array}{l}\text { Papouasie - } \\
\text { Nouvelle- } \\
\text { Guinée } \\
\text { Mongolie }\end{array}$ & $\begin{array}{l}\text { Antigua } \\
\text { Saint- } \\
\text { Christophe } \\
\text { (Saint } \\
\text { Kitts)-et- } \\
\text { Nevis }\end{array}$ & $\begin{array}{l}\text { Azerbaïdj } \\
\text { an } \\
\text { Moldavie }\end{array}$ \\
\hline $\begin{array}{l}\text { Total } \\
2006\end{array}$ & 5 & 4 & 2 & 2 & 2 & 2 \\
\hline \multicolumn{7}{|c|}{2007} \\
\hline Pays & $\begin{array}{l}\text { Rwanda } \\
\text { Malawi }\end{array}$ & $\begin{array}{l}\text { Jamahiriya } \\
\text { libyenne }\end{array}$ & $\begin{array}{l}\text { Guatemala } \\
\text { Pérou } \\
\text { Bolivie } \\
\text { Equateur }\end{array}$ & $\begin{array}{l}\text { Bangladesh } \\
\text { Vietnam }\end{array}$ & $\begin{array}{l}\text { Sainte-Lucie } \\
\text { Saint- } \\
\text { Vincent-et- } \\
\text { Grenadines }\end{array}$ & $\begin{array}{l}\text { Ukraine } \\
\text { Kirghizist } \\
\text { an }\end{array}$ \\
\hline $\begin{array}{l}\text { Total } \\
2007\end{array}$ & 2 & 1 & 4 & 2 & 2 & 2 \\
\hline \multicolumn{7}{|c|}{2008} \\
\hline Pays & $\begin{array}{l}\text { Congo (Rép.) } \\
\text { Guinée } \\
\text { équatoriale } \\
\text { Swaziland } \\
\text { Togo }\end{array}$ & $\begin{array}{l}\text { Bahrain } \\
\text { (Royaume) } \\
\text { Jordanie } \\
\text { Liban } \\
\text { Mauritanie }\end{array}$ & $\begin{array}{l}\text { Cuba } \\
\text { Dominicaine } \\
\text { (Rép.) } \\
\text { Nicaragua }\end{array}$ & $\begin{array}{l}\text { Fiji } \\
\text { Philippines }\end{array}$ & $\begin{array}{l}\text { Anguille } \\
\text { Bermudes } \\
\text { Guyane }\end{array}$ & $\begin{array}{l}\text { Albanie } \\
\text { Tadjikista } \\
\mathrm{n}\end{array}$ \\
\hline $\begin{array}{l}\text { Total } \\
2008\end{array}$ & 4 & 4 & 3 & 2 & 3 & 2 \\
\hline \multicolumn{7}{|c|}{2009} \\
\hline Pays & Sierra Leone & & & & & \\
\hline $\begin{array}{l}\text { Total } \\
2009 \\
\end{array}$ & 1 & & & & & \\
\hline
\end{tabular}

\begin{tabular}{|l|l|l|l|l|l|l|}
\hline $\begin{array}{l}\text { Total } \\
2005 \text { à } \\
2009\end{array}$ & 15 & 11 & 12 & 10 & 10 & 7 \\
\hline $\begin{array}{l}\text { Total } \\
\text { mondi } \\
\text { al }\end{array}$ & \multicolumn{7}{|c|}{65} \\
\hline
\end{tabular}


ANEXO 4 - RELAÇÃO DAS AÇÕES DE COOPERAÇÃO TÉCNICA INTERNACIONAL PRESTADAS PELA EMPRESA BRASILEIRA DE CORREIOS E TELÉGRAFOS NO PERÍODO DE 1995 A 2009

\begin{tabular}{|c|c|}
\hline $\begin{array}{l}\text { Países onde houve a formula } \\
\text { Desenvolvimento Postal com a } \\
\text { Brasileira de Correios e Telégrafo }\end{array}$ & $\begin{array}{l}\text { Refor } \\
\text { da Em }\end{array}$ \\
\hline País & Ano \\
\hline Paraguai & \\
\hline Costa Rica & 2005 \\
\hline Panamá & \\
\hline Colômbia & \\
\hline São Cristóvão (Saint Kitts) e Nevis & 2006 \\
\hline Guatemala & \\
\hline Peru & 2007 \\
\hline Equador & \\
\hline
\end{tabular}

Fonte: Departamento Internacional

Países em que a ECT participou de missão em conjunto com a Agência Brasileira de Cooperação/Ministério das Relações Exteriores

\begin{tabular}{|l|c|}
\hline \multicolumn{1}{|c|}{ País } & Ano \\
\hline Paraguai & \\
\hline México & 2006 \\
\hline Costa Rica & \\
\hline Nicarágua & \\
\hline Paraguai & \\
\hline México & 2007 \\
\hline Suriname & \\
\hline
\end{tabular}




\begin{tabular}{|l|c|}
\hline Guiana & \\
\hline Paraguai & 2009 \\
\hline
\end{tabular}

Fonte: Departamento Internacional

\begin{tabular}{|l|c|}
$\begin{array}{l}\text { Países em que a ECT participou de missão de cooperação técnica por } \\
\text { iniciativa do Ministério das Comunicações }\end{array}$ & Ano \\
\hline \multicolumn{1}{|c|}{ País } & 2006 \\
\hline Venezuela & \multirow{2}{*}{2007} \\
\hline Argentina & \\
\hline Peru & \\
\hline Uruguai & \\
\hline Colômbia & \\
\hline Equador & \\
\hline Uruguai & \\
\hline Uruguai & \\
\hline Argentina & \\
\hline Colômbia & \\
\hline Chile & \\
\hline Bolívia & \\
\hline
\end{tabular}

Fonte: Departamento Internacional

Países com os quais a ECT mantém ou manteve acordo/memorando de entendimento para prestação de cooperação técnica e o ano em que houve ações decorrentes deste instrumento

\begin{tabular}{|l|c|}
\hline \multicolumn{1}{|c|}{ País } & $\begin{array}{c}\text { Ano de } \\
\text { realização de } \\
\text { cooperação } \\
\text { técnica } \\
\text { (bilateral) }\end{array}$ \\
\hline Cuba & 1997 \\
\hline Cabo Verde & 2002 \\
\hline Cuba & 2003 \\
\hline
\end{tabular}




\begin{tabular}{|l|c|}
\hline Cabo Verde & 2004 \\
\cline { 1 - 1 } Chile & 2005 \\
\cline { 1 - 1 } Paraguai & \\
\cline { 1 - 1 } Peru & \\
\hline Cuba & \\
\hline
\end{tabular}

Fonte: Departamento Internacional

Países em que a ECT prestou cooperação técnica por meio de alguma Organização internacional (cooperação multilateral)

\begin{tabular}{|l|l|l|}
\hline \multicolumn{1}{|c|}{ País } & Organização Internacional & \multirow{2}{*}{ Ano } \\
\hline Argentina & UPU & \multirow{2}{*}{1995} \\
\hline Costa Rica & UPU/UPAEP & \\
\hline Paraguai & UPU & \\
\hline Peru & UPU & \multirow{2}{*}{1996} \\
\hline República Dominicana & UPAEP & \\
\hline Cabo Verde & UPU & \\
\hline Guiné Bissau & UPU & \\
\hline Moçambique & UPU & \\
\hline Costa Rica & UPU & \\
\hline Panamá & UPU & \\
\hline Paraguai & UPU & \\
\hline Paraguai & UPU & \\
\hline Angola & UPU/AICEP & \\
\hline Chile & UPU & \\
\hline Costa Rica & UPU & \\
\hline Moçambique & UPU/AICEP & \\
\hline Panamá & UPU & \\
\hline Paraguai & UPU & \\
\hline Peru & UPU/AICEP & \\
\hline Portugal & \multicolumn{1}{|c|}{1998} \\
\hline
\end{tabular}




\begin{tabular}{|c|c|c|}
\hline São Tomé e Príncipe & UPU/AICEP & \\
\hline Venezuela & UPU & \\
\hline República Dominicana & UPAEP & \multirow{2}{*}{1999} \\
\hline Costa Rica & UPU & \\
\hline Bolívia & UPU & \multirow{7}{*}{2001} \\
\hline Colômbia & UPAEP & \\
\hline El Salvador & UPU & \\
\hline Honduras & UPU & \\
\hline Panamá & UPU & \\
\hline Paraguai & UPU & \\
\hline Venezuela & UPU & \\
\hline Angola & UPU & \multirow[b]{2}{*}{2002} \\
\hline República Dominicana & UPU & \\
\hline Angola & AICEP & \multirow{5}{*}{2003} \\
\hline Bolívia & UPAEP & \\
\hline Colômbia & UPU & \\
\hline Costa Rica & UPU & \\
\hline Equador & UPAEP & \\
\hline Angola & UPU & \multirow{6}{*}{2004} \\
\hline Colômbia & UPU & \\
\hline EUA & UPAEP & \\
\hline México & UPU & \\
\hline Nicarágua & UPAEP & \\
\hline Peru & UPAEP & \\
\hline Colômbia & UPAEP & \multirow{6}{*}{2005} \\
\hline Costa Rica & UPU & \\
\hline Guatemala & UPAEP & \\
\hline Panamá & UPU & \\
\hline Paraguai & UPU & \\
\hline Venezuela & UPU & \\
\hline Colômbia & UPU & \\
\hline
\end{tabular}




\begin{tabular}{|l|l|c|}
\hline Costa Rica & UPU & \multirow{2}{*}{2006} \\
\hline Uruguai & UPAEP & \multirow{2}{*}{2007} \\
\hline Argentina & UPU & \\
\hline Costa Rica & UPU & \\
\hline Uruguai & UPAEP & \multirow{2}{*}{2008} \\
\hline Costa Rica & UPU & \\
\hline Portugal & UPU/AICEP & \\
\hline
\end{tabular}

Obs.: Excluídas as cooperações referentes ao PIDEP e as convocadas pelo Ministério das Comunicações

Fonte: Departamento Internacional

Ações de cooperação técnica desenvolvidas pela ECT, no Brasil, período 1995-2009

\begin{tabular}{|c|c|c|c|}
\hline Local & Tipo de Ação & Países Participantes & Ano \\
\hline Petrópolis & Capacitação & Chile; Costa Rica Venezuela & \\
\hline Brasília & Curso & $\begin{array}{l}\text { Angola; Cabo Verde; Guiné-Bissau; } \\
\text { Macau; Moçambique; Portugal; São } \\
\text { Tomé e Príncipe }\end{array}$ & 1997 \\
\hline Maceió & Curso & $\begin{array}{l}\text { Argentina; Bolívia; Chile; Paraguai; } \\
\text { Uruguai }\end{array}$ & \\
\hline Recife & Curso & $\begin{array}{l}\text { Angola; Cabo Verde; Moçambique; } \\
\text { Portugal; São Tomé e Príncipe }\end{array}$ & 1998 \\
\hline Rio de Janeiro & Curso & $\begin{array}{l}\text { Argentina; } \quad \text { Aruba; } \\
\text { Colômbia; Costa rica; }\end{array}$ & 1999 \\
\hline Petrópolis & Curso & $\begin{array}{l}\text { Angola; Cabo Verde; Guiné-Bissau; } \\
\text { Moçambique; Macau; Portugal; São } \\
\text { Tomé e Príncipe }\end{array}$ & \\
\hline
\end{tabular}




\begin{tabular}{|c|c|c|c|}
\hline Rio de Janeiro & Capacitação & $\begin{array}{l}\text { Angola; Cabo Verde; Guiné-Bissau; } \\
\text { Macau; Moçambique; Portugal; S. } \\
\text { Tomé e Príncipe }\end{array}$ & 2000 \\
\hline Rio de Janeiro & Seminário & $\begin{array}{l}\text { Antilhas Holandesas; Argentina; } \\
\text { Aruba; Bolívia, Canadá; Chile; } \\
\text { Colômbia; Costa Rica; Cuba; el } \\
\text { Salvador; Equador; Guatemala; } \\
\text { Nicarágua; Paraguai; Peru; Portugal; } \\
\text { República Dominicana; Uruguai; } \\
\text { Venezuela }\end{array}$ & \multirow[t]{2}{*}{2001} \\
\hline Rio de Janeiro & Seminário & Brasil; Costa Rica; Cuba; Venezuela & \\
\hline Brasília & Conferência & $\begin{array}{l}\text { França; Guatemala; Guiana; Haiti; } \\
\text { Honduras; Itália; Japão; Nicarágua; } \\
\text { Holanda; Paraguai; Portugal; } \\
\text { Uruguai }\end{array}$ & \multirow{2}{*}{2002} \\
\hline Rio de Janeiro & Curso & $\begin{array}{l}\text { Argentina; Colômbia; } \quad \text { Cuba; } \\
\text { Equador; Guatemala; Paraguai; } \\
\text { Peru; República Dominicana; } \\
\text { Venezuela }\end{array}$ & \\
\hline Rio de Janeiro & Seminário & $\begin{array}{l}\text { Bolívia; Cuba; Equador; Paraguai; } \\
\text { Peru; República Dominicana; } \\
\text { Venezuela }\end{array}$ & \multirow[b]{2}{*}{2003} \\
\hline Brasília & Fórum & $\begin{array}{l}\text { Argentina; Bolívia; Costa Rica; } \\
\text { Cuba; El Salvador; Ecuador; EUA; } \\
\text { Guatemala; República Dominicana; } \\
\text { Uruguai }\end{array}$ & \\
\hline Brasília & Worhshop & $\begin{array}{l}\text { Canadá; Chile; Colombia; Cuba; } \\
\text { Ecuador; Nicaragua; Panamá; } \\
\text { Paraguai; Portugal; Venezuela }\end{array}$ & \multirow[b]{2}{*}{2004} \\
\hline Brasília & Curso & $\begin{array}{l}\text { Angola; Cabo Verde; Guiné-Bissau; } \\
\text { Mozambique; Portugal; São Tomé e } \\
\text { Príncipe; Equador; el Salvador; }\end{array}$ & \\
\hline
\end{tabular}




\begin{tabular}{|c|c|c|c|}
\hline & & Nicarágua; Panamá; Paraguai & \\
\hline Salvador & Curso & $\begin{array}{l}\text { Bolívia; Chile; Costa Rica; Cuba; } \\
\text { Equador; Honduras; } \\
\text { panamá; } \quad \text { Paraguaígua; } \\
\text { Venezuela }\end{array}$ & \multirow{3}{*}{2005} \\
\hline Petrópolis & Curso & $\begin{array}{l}\text { Angola; Cabo Verde; Guiné Bissau; } \\
\text { Moçambique; Portugal; São Tomé e } \\
\text { Príncipe; Uruguai e Venezuela }\end{array}$ & \\
\hline Fortaleza & Curso & $\begin{array}{l}\text { Angola; Cabo Verde; Chile; Costa } \\
\text { Rica; Cuba; Equador; Guiné-Bissau; } \\
\text { Macau; Moçambique; Peru; } \\
\text { Portugal; São Tomé e Príncipe }\end{array}$ & \\
\hline Brasília & Simpósio & $\begin{array}{l}\text { Alemanha; Canadá; Costa Rica; } \\
\text { Dinamarca; Espanha; França; Grã- } \\
\text { Bretanha; Guatemala; Itália; Países } \\
\text { Baixos; Peru, Portugal; Suíça; } \\
\text { Venezuela }\end{array}$ & \multirow{3}{*}{2006} \\
\hline Brasília & Seminário & $\begin{array}{l}\text { Colômbia; Costa Rica; } \text { Espanha; } \\
\text { Honduras; Nicarágua; } \\
\text { Paraguai; } \\
\text { Portugal; Uruguai }\end{array}$ & \\
\hline Curitiba & Curso & $\begin{array}{l}\text { Angola; Cabo Verde; Costa rica; } \\
\text { Cuba; Guiné-Bissau; Moçambique; } \\
\text { Paraguai; Portugal; São Tomé e } \\
\text { Príncipe; Venezuela }\end{array}$ & \\
\hline Brasília & Workshop & $\begin{array}{l}\text { Bolívia; Chile; Colômbia; Costa } \\
\text { Rica; Cuba; Haiti; República } \\
\text { Dominicana; Uruguai; Veneuela }\end{array}$ & 2007 \\
\hline Brasília & Capacitação & Peru; Uruguai & 2008 \\
\hline
\end{tabular}

Fonte: Departamento Internacional 
Países que tiveram profissionais formados no Curso de Administração Postal no período $1995-2009$

País

Ano

Bolívia

Borundi

Cabo Verde

Cuba

Guiné

Guiné Equatorial

1995 a

Honduras

Iêmen

Moçambique

São Tomé e Príncipe

Fonte: Departamento Internacional 


\title{
NOTAS
}

\begin{abstract}
${ }^{1}$ Os Estados Unidos, conquanto idealizadores da organização, não obtiveram a aprovação do Senado para aprovação do Tratado de Varsóvia e, por conseguinte, não integraram a Liga. A Alemanha, perdedora da Primeira Guerra Mundial, somente foi aceita em 1926, retirando-se em 1933 e a então União Soviética, que também não participou da 'fundação' da Liga, associou-se no ano de 1934 e foi expulsa em 1939. O Brasil, 'sócio-fundador', retirou-se em 1926.
\end{abstract}

${ }^{2}$ O Presidente dos Estados Unidos da América, Franklin D. Roosevelt e o Primeiro Ministro do Reino Unido, Winston Churchill, elaboraram uma declaração de princípios, conhecida como "Carta do Atlântico", documento precursor e pilar para a criação da Organização das Nações Unidas.

320 países latino-americanos, entre os quais estava o Brasil participaram das tratativas e redação dos 19 capítulos e 111 artigos da Carta de São Francisco e foram seus signatários.

${ }^{4}$ O Conselho de Segurança das Nações Unidas era formado por 15 países-membros dos quais cinco permanentes que possuíam o poder de veto. Desta forma, China, Estados Unidos, França, Inglaterra e Rússia garantiam que apenas aquelas decisões que estivessem aderentes aos seus interesses seriam adotadas.

${ }^{5} \mathrm{Na}$ prática, porém, a atualização plena do termo ocorreu somente nos anos 1970, por pressão dos países do Sul nos foros das Nações Unidas.

${ }^{6}$ Podem ser exemplificadas as seguintes ferramentas: pactos, tratados e alianças político-estratégicas, cooperação militar, além de formas de persuasão e até meios coercitivos.

${ }^{7}$ A Ajuda Alimentar e a Cooperação Científica e Tecnológica não são modalidades freqüentes de cooperação para o desenvolvimento.

8 Quando se estabelece cooperação em C\&T entre países com níveis muito assimétricos de desenvolvimento científico e tecnológico que implica na "transferência" de tecnologia e não o intercâmbio recíproco de conteúdos tecnológicos.

9 Insegurança Alimentar existe quando as pessoas não têm acesso à quantidade de alimentos suficientes, seguros e nutritivos e, portanto, não consomem o indispensável para que possam levar uma vida saudável e ativa. Pode ocorrer por falta de disponibilidade de alimentos, de poder de compra ou por uma inadequada distribuição dos alimentos no âmbito familiar.

10 Direitos Humanos, Meio Ambiente e Não-proliferação foram alguns dos temas globais cujas postulações brasileiras eram protecionistas, rígidas e conservadoras.

${ }^{11}$ O Chanceler do Governo FHC no primeiro mandato (1995-1998) foi o Embaixador Luiz Felipe Lampreia e no segundo mandato (1999-2002), o próprio Embaixador Luiz Felipe Lampreia até janeiro de 2001 e o Embaixador Celso Lafer, no restante do período.

${ }^{12}$ Constitucionalmente, a definição da política externa brasileira é função do Poder Executivo ao tempo que à diplomacia corresponde a responsabilidade da implementação.

${ }^{13}$ No Brasil, constitui serviço postal o recebimento, expedição, transporte e entrega de objetos de correspondência, valores e encomendas (Lei 6.538 de 15 de agosto de 1979)

${ }^{14}$ Os Países-membros da União Postal Universal definiram que para atender à Declaração Universal dos Direitos Humanos, os Estados se incumbem de oferecer a todos os seus cidadãos um conjunto mínimo de serviços denominado "Serviço Postal Universal”. A esta cesta básica de serviços postais somam-se fatores como acessibilidade, qualidade de serviço, custo baixo entre outros requisitos. Esta atividade não interessa à iniciativa privada face ao seu caráter economicamente deficitário.

${ }^{15}$ Em 1874, 22 países assinaram o Tratado de Berna (Suíça) prevendo a fundação da União Geral dos Correios (rebatizada União Postal Universal em 1878). 
${ }^{16}$ Os Países-membros indicam em que medida se comprometem a respeitar os Atos e determinam quais serão as entidades que fornecerão os serviços necessários para o cumprimento das suas obrigações.

${ }^{17}$ Estatística oficial da UPU, ano 2007, disponível em www.upu.int, acessado em 02/03/2010.

${ }^{18}$ Cada país designa seus representantes plenipotenciários por meio de credenciais oficiais expedidas por cada Governo

${ }^{19} \mathrm{O}$ Congresso pode reunir-se extraordinariamente a pedido ou com o assentimento de, pelo menos, dois terços dos Países membros da União

${ }^{20}$ O Brasil foi sede do XVIII Congresso da União Postal Universal, realizado no ano de 1979, na Cidade do Rio de Janeiro

${ }^{21}$ A Secretaria Internacional da União Postal Universal fica localizada em Berna, Suíça.

${ }^{22}$ O Diretor Geral da UPU eleito para o quadriênio 2009-2012 é o francês Edouard Dayan, reconduzido ao posto no Congresso de Nairobi (2008)

${ }^{23}$ Breve descrição do objetivo 1: A UPU dará uma atenção particular à instauração de um serviço postal universal de melhor qualidade, acessível, seguro, harmonizado e eficaz, podendo responder às necessidades do mercado e dos clientes e favorecer o desenvolvimento do mercado em seu conjunto. A interconexão é um dos principais desafios que deve enfrentar o setor postal nos dias de hoje. Para os Países-membros da UPU, a interconexão das redes postais e, numa medida mais ampla, a interconexão de todos os atores do setor postal é de uma importância capital. Os operadores estão mais interessados nas atividades comerciais, e as iniciativas de cooperação técnica nesta ótica são cada vez mais freqüentes

${ }^{24}$ Breve descrição do objetivo 2: A UPU tem a missão de servir de fórum mundial comum ao setor postal e aos poderes públicos para que uns e outros trabalhem juntos para o desenvolvimento, a adoção e a melhoria de um quadro regulamentar para a prestação e o acesso ao serviço postal universal. A fim de ter êxito nesta área, é necessária uma cooperação técnica do mais alto nível

${ }^{25}$ Breve descrição do objetivo 3: Fornecer apoio e assistência aos Países-membros nos seus esforços de realização do objetivo da UPU visando a promoção do desenvolvimento sustentável do setor postal tridimensional com base num território postal único

${ }^{26}$ Breve descrição do objetivo 4: Todos os atores postais (governo, regulador, operador postal público, outros operadores, outros atores, etc.), devem adotar as medidas necessárias referentes às questões ligadas ao desenvolvimento do mercado postal a fim de satisfazer às exigências dos clientes

${ }^{27}$ A Carta de Caminha narrando sobre as terras descobertas existe até hoje, no seu original, guardada na Torre do Tombo, em Lisboa, Portugal. O inteiro teor pode ser lido no site: http://www.correios.com.br/institucional/conheca_correios/historia_correios/historia_correios_brasil.c fm\#top (Institucional $>$ Conheça os Correios $\gg$ História dos Correios $\gg$ Carta de Pero Vaz Caminha)

${ }^{28}$ Recorda-se que nesse período a exploração do ouro em Minas Gerais estava em grande desenvolvimento

${ }^{29}$ O primeiro selo do mundo é conhecido como "Penny Black" e foi criado na Inglaterra em 1840 decorrente de uma reengenharia organizacional coordenada por Rowland Hill. Até então, o pagamento pela prestação do serviço postal, que inclui as etapas de transporte e distribuição, era efetuado pelo destinatário que não tinha obrigatoriedade de aceitar o recebimento da correspondência.

${ }^{30}$ O Supremo Tribunal Federal decidiu manter o monopólio postal da Empresa Brasileira de Correios e Telégrafos no julgamento da Argüição de Descumprimento de Preceito Fundamental (ADPF 46) ajuizada em 2003 pela Associação Brasileira das Empresas de Distribuição (Abraed). O julgamento ocorreu em 05/08/2009.

${ }^{31}$ Fonte: ECT - Relatório de Avaliação Empresarial - Referência: Novembro/2009 
${ }^{32}$ Fonte: ECT - Relatório Gerenciamento de Pessoal Simplificado (GPS) da Diretoria de Gestão de Pessoas - Referência: Dezembro/2009

${ }^{33}$ Fonte: ECT - Relatório de Avaliação Empresarial - Referência: Novembro/2009

${ }^{34}$ Fonte: ECT - Relatório de Avaliação Empresarial - Referência: Novembro/2009

35 Fonte: IBGE - Pesquisa Nacional por Amostra de Domicílios (PNAD 2006) - publicado no relatório de Estudos e Pesquisas - Informação Demográfica e Socioeconômica: Síntese de Indicadores Sociais - Uma Análise das Condições de Vida da População Brasileira (2007), disponível em http://www.ibge.gov.br/home/estatistica/populacao/condicaodevida/indicadoresminimos/sinteseindics ociais2007/indic sociais2007.pdf, acesso em 02/03/2010

${ }^{36}$ Em 2009, a ECT promoveu 2 planos de desligamento voluntário. Em dezembro/2008 o seu efetivo total era de 112.329 empregados, explicando-se assim o percentual de carteiros de 50,49\% em 2008 e $51,8 \%$ em 2009

37 Deixamos de apresentar o Plano Estratégico 2009 versão revisada do Plano Estratégico 2004 2007/2008 por se tratar de documento interno cuja publicação não é autorizada

${ }^{38}$ Disponível no site:

http://www.correios.com.br/institucional/conheca_correios/relatorios_publicacoes/relatorios_empresar iais/2008/Relatorio_ECT_2008.pdf, acesso em 21/03/2010 